Discussion

Papers

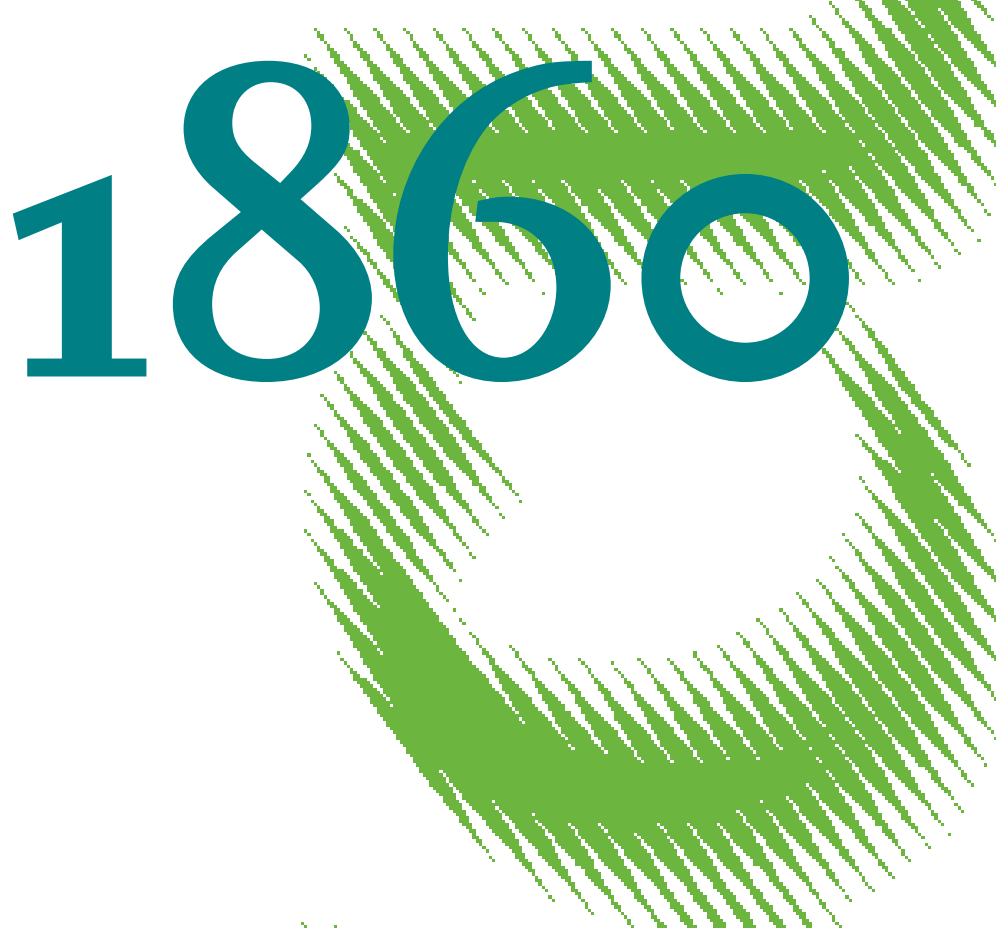

alil

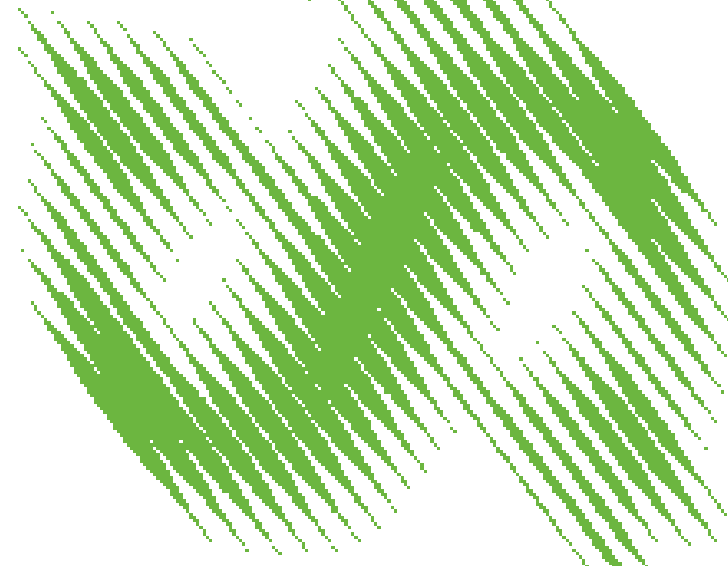

The Financial Accelerator, Wages, and Optimal Monetary Policy 
Opinions expressed in this paper are those of the author(s) and do not necessarily reflect views of the institute.

IMPRESSUM

(C) DIW Berlin, 2020

DIW Berlin

German Institute for Economic Research

Mohrenstr. 58

10117 Berlin

Tel. +49 (30) $89789-0$

Fax +49 (30) $89789-200$

http://www.diw.de

ISSN electronic edition 1619-4535

Papers can be downloaded free of charge from the DIW Berlin website:

http://www.diw.de/discussionpapers

Discussion Papers of DIW Berlin are indexed in RePEc and SSRN:

http://ideas.repec.org/s/diw/diwwpp.html

http://www.ssrn.com/link/DIW-Berlin-German-Inst-Econ-Res.html 


\title{
The Financial Accelerator, Wages, and Optimal Monetary Policy
}

\author{
Tobias König*
}

April 1, 2020

This paper studies the effects of labor market outcomes on firms' loan demand and on credit intermediation. In a first step, I investigate how wages in the production sector affect bank net worth and the process of financial intermediation in partial equilibrium. Second, the role of the identified channels are studied in general equilibrium using a newKeynesian DSGE-model with financial frictions and an endogenous financial accelerator mechanism. Third, I investigate how perfect and imperfect labor markets, in a setting with interactions between production factor costs and the intermediation of credit, affect the transmission mechanism of monetary policy. The analysis reveals that financial frictions reduce the factor demand elasticity of capital to a change in wages. This finding is relevant for the determination of optimal monetary policy, both for financial shocks and supply shocks inflation stabilization imposes high welfare costs. At the same time, stabilizing nominal wages becomes welfare beneficial by reducing both the volatility of the credit spread and the output gap.

Keywords: financial accelerator; monetary policy; nominal rigidities, factor costs.

JEL Classification Numbers: E31, E44, E52, E58.

*DIW Berlin, Mohrenstraße 58, 10117 Berlin and Humboldt-Universität zu Berlin, Spandauer Straße 1, 10178 Berlin, email: tkoenig@diw.de. This paper was written in the context of the SAW-project "European capital markets and macroeconomic stability: The role of equity and debt." Funding from the Leibniz Competition is gratefully acknowledged. In particular I am thankful to Michael C. Burda, Alexander Kriwoluzky, Kalin Nikolov, Alexander Haas, Franziska Bremus, Lutz Weinke, Thomas Dengler, Caterina Mendicino, Mathias Trabandt, Adrian Ochs, and Stephanie Schmitt-Grohé for many valuable comments and advice. Any and all errors are entirely my own. 


\section{Introduction}

The financial crisis in 2007 shows that financial intermediation itself can be a source of endogenous risk and the cause of economic downturns. While the effects of banking frictions on the goods-producing sector received increasing attention since the downturn, the implications of labor market outcomes on the loan demand of firms and on the process of financial intermediation itself is not widely investigated. A growing strand of literature attributes the phenomena of jobless recoveries observed after the Great Recession to financial frictions or, at least, to financial shocks. Several papers demonstrate a tight linkage between borrowing constraints, credit supply, and wage setting (see, among others, Michelacci and Quadrini 2009 and ElFayoumi 2018). However, these analyses focus on the implications for the firm sector, with little known about the reverse channel, namely how wages in the production sector affect bank profits.

The question regarding how far wages, which contribute the largest share to firms' marginal costs, affect the net worth of banks through interactions with capital demand, remains open in the literature. In this paper, I study in detail the interactions between both factor costs and the intermediation of credit from banks to goods-producing firms. Taking these interactions into account, I investigate how perfect and imperfect labor markets in that setting affect the transmission mechanism of monetary policy. In this way, I also contribute to the debate about the optimal implementable monetary policy rule in the presence of credit spreads and the existence of a financial accelerator.

This paper contributes to the literature by using a quantitative new-Keynesian dynamic stochastic general equilibrium (NK-DSGE) model with financial frictions and an endogenous financial accelerator mechanism investigating the role of wage setting for the intermediation of credit both in partial and general equilibrium. The financial sector is modelled as in from Gertler and Karadi (2011). To investigate how wages affect the demand for loans and, eventually, banks' profitability in a financial crisis, the analysis starts by outlining two channels in partial equilibrium after a con- 
tractionary financial shock. First, a substitution channel under which lower wages diminish capital demand of firms by decreasing the costs of labor. ${ }^{1}$ This reduction in capital input then translates into a lower demand for loans, contracting banks' net worth. Then, in general equilibrium, the substitution channel affects the price of banks' assets via the demand for capital. This financial accelerator mechanism has a large effect on aggregate output. The second channel is a scale effect channel of wages. Lower wages reduce firms' costs, ceteris paribus, boosting aggregate output and increasing, in relative terms, the demand for both capital and labor. This increase in capital demand in turn has a beneficial effect on banks' net worth and mitigates the effects of the substitution effect channel. Both channels also exist in general equilibrium; hence, wages play a crucial role in determining optimal monetary policy under different scenarios. I do so by computing the welfare implications of implementable simple monetary policy rules and the time-less Ramsey optimal policy under commitment.

Business cycle shocks in presence of financial frictions cause fluctuations in the spread between borrowing rates and the risk-free rate. As highlighted by De Paoli and Paustian (2017), these fluctuating credit spreads cause a misallocation of production factors. Thus, the spread between borrowing rates and the risk-free rate becomes a welfare-relevant object.

The findings for optimal monetary policy are twofold. First, inflation stabilization implies high welfare costs after both financial shocks and supply side shocks. A trade-off between stabilizing inflation and stabilizing credit spread volatility implies that primarily focusing on inflation comes with the cost of stark financial amplification of shocks and, eventually, high welfare costs. This is primarily due to demand shifting properties of financial frictions, lowering both output and inflation, plus distortionary effects on the relative composition of production factors. In contrast to De Paoli and Paustian (2017), endogenous capital and not labor input is distorted

\footnotetext{
${ }^{1}$ The analysis in the stylized partial equilibrium model mimic a sequence of contractionary shocks lowering capital, labor, and wages, as observed during the Great Recession. See Christiano et al. (2015) for a detailed discussion about the underlying shocks and the behavior of these variables during the Great Recession.
} 
by financial frictions. While borrowing frictions on labor input have an endogenous cost-push effect, borrowing frictions on capital act, in line with De Groot and Haas (2019), as a demand shifter. Falling marginal costs reduce the borrowing rate and the credit spread. Stabilizing inflation and, eventually, marginal costs in a recession in which inflation and output co-move, thus can have adverse effects on the volatility of the credit spread, distorting the capital allocation further. Finally, the demand shifting property of the credit spread eventually increases the importance of the substitution effect channel from above.

Second, in this context, stabilizing nominal wage growth after a financial shock, simultaneously reduces the volatility of the credit spread and closes the output gap, even under flexible nominal wages. The reason is the adverse effects of wage setting on capital demand after such shocks and the resulting adverse effects of the financial accelerator. By stabilizing real wages, the volatility of labor productivity is reduced. Optimally, capital gets less substituted and this affects the expected future costs of capital in relative terms. The price of capital stabilizes, which beneficially affects bank profitability. Further, after a contractionary shock, keeping nominal wages relatively constant causes an increase in firms' nominal marginal costs and inflation rises. This rise in inflation, together with a lowering of the policy rate, let the real risk-free rate drop. A lower expected path of the risk-free rate shrinks in addition the credit spread, and mitigates the financial accelerator effect on output.

The remainder of this paper is structured as follows. Section 2 gives a short overview of the related literature. Section 3 introduces the partial equilibrium banking model and illustrates how real wages impact banks' profitability. Section 4 outlines the general equilibrium version of the model. In section 5, the benchmark version of the general equilibrium model is estimated. Section 6 presents results regarding the effects of the nominal wage setting on loan demand and bank net worth. In section $7, \mathrm{I}$ comment on optimal monetary policy rule and compare the welfare costs of a variety of policy rules. Robustness checks and the determinacy behavior of the model are discussed in section 8. Section 9 concludes. 


\section{Related Literature}

The events of the financial crisis in 2007/08 gave birth to a strand of literature that incorporates frictions in the banking sector in dynamic stochastic general equilibrium models (see, among others, Gertler and Kiyotaki (2010), Gerali et al. (2010) and Gertler and Karadi (2011)). The effects of banking frictions on the goods-producing sector is gaining ever increasing attention. However, the impact of wage setting on the process of financial intermediation is not the subject of much investigation.

The first strand of related literature emerged after the Great Recession, combining financial frictions with the labor market. The aim of several of these contributions was to explain the jobless recovery phenomena. One of the most influential papers in this area is Hall (2011), which connects household leverage, financial frictions, and the zero lower bound to explain the long period of jobless recovery. Mian and Sufi (2014) provide empirical evidence that a persistent decline in non-tradeable employment after the Great Recession occurred, particularly in regions in which households were hit by large housing net worth shocks. These two papers focus more on financial shocks and financial frictions originating on the household side of the economy. I contribute to this literature by focusing instead on the interaction between employment and firm leverage.

One paper explicitly analyzing the effects of borrowing constraints on firms' wage profile is Michelacci and Quadrini (2009). It shows that firms that are more borrowing constraint on financial markets are characterized by lower employment levels and pay lower wages. Jaimovich and Siu (2012) find a disappearance of routine jobs in downturns, which suggests that routine tasks were automated by installing additional capital. These findings imply that wage profiles and employment decisions have a direct impact on loan demand and vice versa. In this paper, I connect those findings with the literature on financial accelerators. A closely related paper is ElFayoumi (2018), which investigates the effects of credit expansions on firms output, employment, and aggregate real wages in both an empirical and a theoretical heterogeneous firm model. Positive credit supply shocks are found to be expansion- 
ary in output and employment but they decrease real wages and the labor share. Yet little is known in the literature about the reverse channel, how, in turn, wage setting affects loan demand and, eventually, the profits of banks under imperfect financial markets. My paper fills this gap in the literature.

The second strand of literature is on the interaction between optimal monetary policy and financial frictions. Early contributions to this literature abstracted from either endogenous financial amplification or from spreads in interest rates (see, among others, Carlstrom and Fuerst (2001), Ravenna and Walsh (2006), and Demirel (2009)). Although financial frictions give rise to endogenous cost-push effects - causing a trade-off between zero inflation and small output gaps - inflation stabilization remains close to optimal in those papers. Offsetting the distortions caused by nominal price frictions is also welfare optimal in the financial frictions model of Carlstrom et al. (2010). The benefits of deviation from complete inflation stabilization are minor, a finding also made by Fiore and Tristani (2013) and De Paoli and Paustian (2017). Cúrdia and Woodford (2016) show that for financial shocks, price stability remains the main target for policy makers. However, all these papers abstract either from endogenous capital, from a banking sector or from both. De Groot and Haas (2019) document that the nature of the credit spread changes under borrowing frictions on endogenous capital. Instead of the cost-push effect, a demand shifting effect prevails. My paper includes both endogenous capital and a banking sector.

In doing so, I am closely related to the sub-strand of literature on optimal monetary policy and financial intermediation that emerged since 2007/08. Gambacorta and Signoretti (2014) investigate the monetary policy implications of a variety of macroeconomic and financial supply side shocks in a model with frictions in the banking sector. For supply-side shocks, they show that by responding to credit or asset prices, central banks achieve a much better trade-off between inflation and output gap stabilization. Aggressive regimes targeting inflation are less effective and more welfare costly. The finding of high welfare costs of inflation stabilization in a financial accelerator model is also made by Nisticò (2016) and Hansen (2018). 


\section{Wages and bank net worth in the partial equilibrium}

In this section, I investigate the interaction between the level of real wages and bank profits in a simple two period partial equilibrium model of banks and goodsproducing firms. The aim of this section is to illustrate the key mechanisms of the general equilibrium in the upcoming sections in a tractable way that nevertheless includes the key features of new-Keynesian DSGE banking models. The results of this section relates to Higgs' third law and the determination of capital factor demand. The banking sector is a two-period version of the financial sector in Gertler and Karadi (2011).

\subsection{A two-periods model}

\subsubsection{The bank in the PE model}

A representative bank is endowed with initial net worth $N_{1}$. At the beginning of the first period, the bank provide loans $Q_{1} S_{1}$ to a representative goods-producing firm, where $S_{1}$ is the amount of loans and $Q_{1}$ is the price of capital. In order to satisfy firm's loan demand, the bank receives deposits $D_{1}$ from deep-pocket households. The bank's balance sheet is therefore given by

$$
Q_{1} S_{1}=N_{1}+D_{1}
$$

In the second and terminal period, the bank receives a return on loans $R_{2}^{k}$ and has to pay-back its debt to households given the risk-free deposit rate $R_{2}$. The financial intermediary maximizes its net present value of future net worth, given the balance 
sheet constraint and an incentive constraint

$$
\begin{aligned}
& \qquad V_{1}=\max _{N_{2}} \beta N_{2} \\
& \text { s.t } Q_{1} S_{1}=N_{1}+D_{1}, \\
& N_{2}=R_{2}^{k} Q_{1} S_{1}-R_{2} D_{1}, \\
& V_{1} \geq \lambda Q_{1} S_{1} .
\end{aligned}
$$

The incentive constraint $V_{1} \geq \lambda Q_{1} S_{1}$ states that terminal net worth has to be larger or equal to a fraction $\lambda$ of assets. This fraction can be diverted in the initial period by bankers, causing depositing households to suffer a loss and giving rise to a spread between rental rate and risk free rate. In equilibrium the constraint always binds.

Thus, the maximization provides us with a term for leverage

$$
\frac{Q_{1} S_{1}}{N_{1}}=\frac{\beta R_{2}}{\lambda-\beta\left(R_{2}^{k}-R_{2}\right)}
$$

which can be rearranged into a term for the contractual rental rate

$$
R_{2}^{k}=\frac{\lambda N_{1}+\left(\lambda+\beta R_{2}\right) D_{1}}{\beta\left(N_{1}+D_{1}\right)}
$$

\subsubsection{The firm in the PE model}

In the second period, a representative goods-producing firm, combines capital and labor to produce the final good under imperfect competition. The firm faces a demand constraint on the world market

$$
Y_{2}(i)=\left(\frac{P_{2}(i)}{\tilde{P}_{2}}\right)^{-\epsilon} \tilde{Y}_{2}
$$


with $\tilde{P}_{2}$ denoting the average price level and $\tilde{Y}_{2}$ the aggregate demand. The CobbDouglas production function of firm $i$ is defined as:

$$
Y_{2}(i)=\left(\xi_{2} K_{2}(i)\right)^{\alpha}\left(L_{2}(i)\right)^{1-\alpha}
$$

Here $\xi_{2}$ denotes the quality of capital. The firm has to finance its entire capital with loans. The capital stock itself is bought from a capital producer at price $Q_{1}$ at the end of period one, and depreciated capital can be sold back in the end of period two at price $Q_{2}$. The fully specified maximization problem is then

$$
\begin{gathered}
\max _{P_{2}(i), L_{2}(i), K_{2}(i)}=\frac{\epsilon-1}{\epsilon} P_{2}(i) Y_{2}(i)-R_{2}^{k} Q_{1} K_{2}(i)-W_{2} L_{2}(i)+Q_{2}(1-\delta) \xi_{2} K_{2}(i), \\
\text { s.t. } Y_{2}(i)=\left(\xi_{2} K_{2}(i)\right)^{\alpha}\left(L_{2}(i)\right)^{1-\alpha} \\
Y_{2}(i)=\left(\frac{P_{2}(i)}{\tilde{P}_{2}}\right)^{-\epsilon} \tilde{Y}_{2}
\end{gathered}
$$

The firm takes the real rental rate $R_{2}^{k}$ and the real wage $w_{2}$ as given. The first order condition can be solved for both factor inputs, after dropping the index $i$

$$
\begin{aligned}
L_{2} & =\frac{\epsilon-1}{\epsilon} P_{2}(1-\alpha) \frac{\bar{Y}_{2}}{W_{2}} \\
K_{2} & =\left(\frac{R_{2}^{k} Q_{1}-\xi_{2}\left(Q_{2}-\delta\right)}{\frac{\epsilon-1}{\epsilon} P_{2} \alpha L_{2}^{1-\alpha} \xi_{2}^{\alpha}}\right)^{\frac{1}{\alpha-1}}
\end{aligned}
$$

By additionally using the profit function, one can solve for $L_{2}, K_{2}$, and $P_{2}$.

\subsubsection{Partial equilibrium}

The capital demand of firms must satisfy the loan supply of banks

$$
Q_{1} S_{1}=Q_{1} K_{2}
$$

Banks will satisfy this demand by issuing enough loans. To do so, they require a sufficient amount of deposits. Here, the deep-pocketed household will ensure a sufficient funding of the banking sector by receiving the risk-free rate as its return on 


\begin{tabular}{l|cc|cc}
\hline \hline & \multicolumn{2}{|c|}{ Constant output } & \multicolumn{2}{c}{ Constant prices } \\
\hline & I.1 & II.1 & I.2 & II.2 \\
\hline Bank profits & -2.0028 & -1.8136 & -3.6792 & -4.6205 \\
Real price of good & 1.3062 & 2.2347 & 0.0000 & 0.0000 \\
Output & 0.0000 & 0.0000 & -4.6424 & -7.7413 \\
Labor input & 1.3062 & 1.2225 & -4.6242 & -8.6548 \\
Capital input & -2.0028 & -1.8136 & -3.6792 & -4.6205 \\
\hline \hline
\end{tabular}

Table 1: The table summarizes the effects of (I.x) a deterioration of capital quality by one percent, (II.x) a deterioration of capital quality and an increase of real wages both by one percent. In the first two columns, world demand remains constant, invariant to the price changes of the produced good. Under the last two scenarios (I.2) and (II.2) the assumption of fixed demand is relaxed but real good prices remain constant. All reported variables are in percentage deviation from the benchmark calibration.

provided funds. In other words it will provide deposits accordingly to the following supply function, which comes from bank's balance sheets

$$
D_{1}=Q_{1} S_{1}-N_{1}
$$

Now with all the components the model can be solved. The system of equations is given by (2), (3), (4), (5), (6), and (7).

\subsection{Results: Credit shocks and wage setting in the $\mathbf{P E}$}

First, the world demand for goods, initial endowment of banks, the real wage, and the price of capital are all fixed to one for the time being. That is $Y_{2}(i)=\tilde{Y}_{2}=1$. The calibration for the partial equilibrium model is specified in detail in table A1 of appendix A.

In a second step, the price of the consumption good will be fixed, and output adjusts to clear the goods market.

I use the tractable banking model to illustrate several key results that will also hold in general equilibrium in the subsequent section. To this end, I consider four different scenarios, comparing the results for bank profits, marginal costs, and labor demand under these scenarios with the benchmark calibration. The results are summarized in table 1. 


\subsubsection{Constant output (substitution effect)}

Scenario I: Capital quality shock

Under scenario (I.1) the quality of capital in period two, $\xi_{2}$, decreases by one percent. This causes capital demand to drop and diminish bank profits. The firm reacts by increasing its labor input to produce the good. By assumption, real wages are constant in this scenario and labor demand increases. Thus, real marginal costs increase due to the higher labor demand. The firm has to raise the price to offset the increase in marginal costs and makes zero profits.

Scenario II: Capital quality shock + wage shock

In scenario (II.1), capital quality is reduced again by the same amount, but at the same time real wages increase by one percent. One can think about this scenario as two correlated shocks affecting both production factors. ${ }^{2}$ An increase of real wages has the effect that labor becomes more expensive compared to capital. Thus, capital demand rises compared to the previous scenario; as does credit and the bank's terminal net worth. ${ }^{3}$

The case (II.1) of constant world demand describes firms' substitution effect channel for capital demand. Since prices adjust perfectly and output is constant, the increase in labor factor costs changes only the relative composition of production factors.

Capital demand elasticity can be derived within this partial equilibrium model as following: ${ }^{4}$

$$
[\sigma-\epsilon] \frac{\epsilon-1}{\epsilon} \frac{L_{2} *\left(M P L_{2}\right)}{Y_{2}(\epsilon-1)+\frac{N_{1}\left(\epsilon+\sigma \frac{1-\alpha}{\alpha}\right)}{\beta \xi_{2} P_{2}}}
$$

with $\sigma$ denoting the Hicks-Allen elasticity of substitution between capital and labor input and $\epsilon$ the demand price elasticity. The later is equal to zero under constant

\footnotetext{
${ }^{2}$ Think about the wage shock as a upward shift of a horizontal labor supply curve.

${ }^{3}$ Since, in this stylized model, the household side is not included, I abstract from any equilibrium effects on the labor market. Lower labor demand here has no impact on wages. Labor supply thus can be regarded as perfectly elastic with a horizontal supply curve.

${ }^{4}$ The derivation is available in appendix A.1.
} 
output/demand, leaving over the positive term $\sigma$ which explains the rise in capital under this scenario. To my knowledge this is the first paper deriving the capital factor demand elasticity in a model with financial frictions.

The formula for the capital demand elasticity in a two-factor production economy with constant returns to scale and no banking sector, denoted as $\eta_{K, w}^{\text {nobanks }}$, is derived by Hicks (1932) and Hicks (1961). A version with market power under imperfect competition, can be rewritten as:

$\eta_{K, w}^{\text {nobanks }}=[\sigma-\epsilon] \frac{\epsilon-1}{\epsilon} \frac{L_{2} *\left(M P L_{2}\right)}{Y_{2}(\epsilon-1)} \geq[\sigma-\epsilon] \frac{\epsilon-1}{\epsilon} \frac{L_{2} *\left(M P L_{2}\right)}{Y_{2}(\epsilon-1)+\frac{N_{1}\left(\epsilon+\sigma \frac{1-\alpha}{\alpha}\right)}{\beta \xi_{2} P_{2}}}=\eta_{K, w}^{\text {banks }}$.

Hence, the elasticity of capital to a change in real wages becomes smaller in the presence of a banking sector with intermediation frictions. Compared to the case without financial frictions, a rise in real wages lowers capital demand less. ${ }^{5}$

\subsubsection{Constant prices (scale effect)}

The result above changes when I relax the assumption of constant goods demand. In reality an increase in prices would, ceteris paribus, depress demand for goods. For simplicity and tractability I did not want to endogenize both prices and output level in this stylized model. Instead, in a second version of the model, summarized in the last two columns of table 1, I assume that prices are now fixed and cannot be changed, with output adjusting endogenously. ${ }^{6}$

$\underline{\text { Scenario I: Capital quality shock }}$

In this case, described in column I.2, both capital and labor input fall given a negative capital quality shock due to the drop in output.

Scenario II: Capital quality shock + wage shock

The scenario of a simultaneous decline in capital quality and an increase in real wages, column II.2, amplifies both the decline in output and bank net worth relative

\footnotetext{
${ }^{5}$ This less elastic capital demand has a direct effect on asset prices in general equilibrium and, eventually, on the financial accelerator mechanism. For the sake of tractability and for being able to derive the analytic results in equation (8), I abstract from an endogenous accelerator mechanism in partial equilibrium

${ }^{6}$ This mimics the case of completely rigid prices due to price setting frictions.
} 
to scenario I.2. For future reference, I label this channel the scale effect channel of wages, under which an increase in wages depresses capital and loan demand. However, the previously described substitution channel is not absent here, it is only dominated by this second scale effect channel. In the case of the latter general equilibrium model, both channels are active, the one dominating depending on the shock scenario.

The case (II.2) of constant prices describes a case where firms' scale effect channel for capital demand dominates the substitution channel. This is the case when the negative price elasticity term in equation (8) exceeds the substitution elasticity. Firms face high marginal costs under constant prices and an increase in labor factor costs. Output and both production factors are additionally reduced.

I built a stylized model to illustrate the effects of an adverse shock to collateralized assets on banks' profitability and the composition of input factors in the goods market. The chapter works out the differences channels of substitution effect and scale effect for firms' capital demand. The results suggest that bank profits and capital demand deteriorate less if the substitution effect dominates, encouraging firms to substitute capital for labor to satisfy demand for goods. This channel might be from increased importance to monetary policy makers when considering the response to a crisis, such as a worsening of credit conditions. The next sections investigates whether this channel remains meaningful in the general equilibrium.

\section{The model in general equilibrium}

This section builds on the previous partial equilibrium model. The core of the general equilibrium model is a canonical new-Keynesian DSGE model, à la Christiano et al. (2005). As in the previous section, the financial sector is characterized by an agency problem, as in Gertler and Kiyotaki (2010) and Gertler and Karadi (2011). The model includes households, intermediate goods-producing firms, final retailers, capital-producing firms, and financial intermediaries. Finally, the model is closed by a government sector and a central bank conducting monetary policy. I comment 
shortly on the interaction between the different agents, before going into more detail in each subsection.

Workers of monopolistic households possess market power by supplying differentiated labor types that allow for some degree of wage stickiness. Aggregate hours eventually are sold to perfectly competitive intermediate goods-producing firms. The intermediate firms combine labor and capital to produce intermediate goods. Capital, in turn, must be bought from competitive capital producing firms. However, intermediate goods-producing firms must finance their complete capital demand by issuing claims to get loans from financial intermediaries. Banks receive funds from saving households and lend to firms, but intermediation is affected by financial frictions. These frictions are introduced by an agency problem between households and banks. Bankers can divert a certain fraction of assets, transfer the revenue to their own households, and shut down the bank. Eventually, monopolistic retailers sell the final good with a mark-up over competitive marginal costs to households. Both nominal wages and the prices of final goods are not flexible. The government sector is modeled by a simple fiscal policy rule where government expenditures are financed by lump-sum taxes. The central bank provides conventional monetary policy following a Taylor rule.

\subsection{Households}

There exists a continuum of identical households of measure one. Each household is divided into two types of individuals. A fraction $(1-f)$ of each household are workers supplying differentiated labor hours of type $l$ to non-financial firms. Workers receive a nominal wage that is then shared within their households. Another fraction $f$ of each household are bankers, responsible for the intermediation of funds to firms. Each household supplies a number of hours $L_{t}(l)$ and sets the nominal wage $W_{t}(l)$ in favor of its affiliated members. $L_{t}(l)$ is the sum of all labor hours supplied by identical workers within this specific household. Differentiated labor hours are not 
perfectly substitutable and, therefore, households have a degree of market power when setting their wages. As in Erceg et al. (2000), aggregate employment can be written by the following Dixit-Stiglitz expression

$$
L_{t}=\left(\int_{0}^{1} L_{t}(l)^{1-\frac{1}{\epsilon_{w}}} d l\right)^{\frac{\epsilon_{w}}{\epsilon_{w}-1}}
$$

where $\epsilon_{w}$ represents the elasticity of substitution between different kinds of labor. $L_{t}(l)$ denotes the supplied labor of each type $l$. Aggregate labor $L_{t}$ equals the aggregated firms' labor demand. Aggregator's demand for each type of labor $l$ is given by the following constraint

$$
L_{t}(l)=\left(\frac{W_{t}(l)}{W_{t}}\right)^{-\epsilon_{w}} L_{t}
$$

and the wage index

$$
W_{t}=\left(\int_{0}^{1} W_{t}(l)^{1-\epsilon_{w}} d l\right)^{\frac{1}{1-\epsilon_{w}}}
$$

is defined as the average over all individual wage levels $W_{t}(l)$.

Given the labor market structure from above, households will maximize their utility

$$
\max _{\left\{C_{t}(l), D_{t+1}(l), W_{t}(l)\right\}} E_{t} \sum_{i=0}^{\infty} \beta^{i} \zeta_{t+i}^{c}\left[\ln \left(C_{t+i}(l)-h C_{t+i-1}(l)\right)-\frac{\chi}{1+\varphi} L_{t+i}^{1+\varphi}(l)\right],
$$

such that their budget constraint

$$
P_{t+i} C_{t+i}(l)=W_{t+i}(l) L_{t+i}(l)+P_{t+i} \Pi_{t+i}^{R e v}(l)+P_{t+i} T_{t+i}(l)+R_{t+i} \Pi_{t+i} D_{t+i}(l)^{n}-D_{t+i+1}^{n}(l),
$$


labor demand and the wage setting constraint

$$
\begin{aligned}
L_{t+i}(l) & =\left(\frac{W_{t+i}(l)}{W_{t+i}}\right)^{-\epsilon_{w}} L_{t+i} \\
W_{t+i}(l) & =\left\{\begin{array}{l}
W_{t+i}^{*} \text { with probability }\left(1-\gamma_{w}\right) \\
W_{t+i-1}(l) \Pi_{t+i}^{\gamma_{\text {ind, }}} \text { with probability } \gamma_{w}
\end{array}\right.
\end{aligned}
$$

are fulfilled. The parameter $\beta \in(0,1)$ is the household's discount rate, $\chi>0$ denotes disutility from working and the parameter $\varphi>0$ is the inverse Frisch elasticity of labor supply. Shocks to the time preference of households are denoted by $\zeta_{t}^{c}$ and follow an auto-regressive process of order one. $W_{t}(l)$ is the nominal wage paid for labor hours of type $l$. The average price level in the economy is given by $P_{t}$. $\Pi_{t}^{R e v}(l)$ is the share of real profits households earn by owning financial intermediaries and non-financial firms net the start-up transfer households pay to newly founded banks. $T_{t}$ are lump-sum taxes in real terms paid to the government. Every period, households can save by supplying deposits $D_{t+1}^{n}(l)$ to banks, which will pay out

the gross nominal interest rate $R_{t+1} \Pi_{t+1}$ in the next period. $\Pi_{t}=\frac{P_{t}}{P_{t-1}}$ being the gross inflation rate. The timing notation denotes the period in which the contract is paying off.

\subsubsection{Households' optimality conditions}

By maximizing consumption, I obtain the marginal utility of consumption

$$
\varrho_{t}=\frac{\zeta_{t}^{c}}{C_{t}-h C_{t-1}}-h \beta E_{t}\left(\frac{\zeta_{t+1}^{c}}{C_{t+1}-h C_{t}}\right)
$$

Combining this equation (16) with the optimal bond-holding condition yields the household's Euler equation for consumption:

$$
\beta E_{t} \Lambda_{t, t+1} R_{t+1}=1
$$


where $\Lambda_{t, t+1}=\frac{\varrho_{t+1}}{\varrho_{t}}$ is the marginal rate of substitution between current consumption and consumption in the next period.

The second part of the households' maximization problem is defined by their nominal wage decision. Staggered wage setting is introduced following Erceg et al. (2000) using a Calvo (1983) mechanism. Each period, only a fraction $1-\gamma_{w}$ can readjust their nominal wages, the other fraction index their wages to the inflation level. Households set nominal wages such that households' expected utility (12) is maximized subject to households' budget constraint (13) and labor demand (10). The optimal wage fulfills the following first order condition

$$
E_{t} \sum_{i=0}^{\infty} \beta^{i} \zeta_{t+i}^{c} \gamma_{w}^{i} L_{t+i}(l) \varrho_{t+i}\left[\frac{W_{t}^{*}}{P_{t+i}} \prod_{k=1}^{i} \Pi_{t+k-1}^{\gamma_{i n d, w}}-\frac{\epsilon_{w}}{\epsilon_{w}-1} M R S_{t+i}\right]=0
$$

where $M R S_{t+i}$ is the household's marginal substitution between consumption, $\gamma_{\text {ind,w }}$ is the wage indexation parameter and labor, and $\frac{\epsilon_{w}}{\epsilon_{w}-1}$ denoting a constant mark-up. Equation (11) yields, after some rearrangements, the definition of real wages

$$
w_{t}^{1-\epsilon_{w}}=\left(1-\gamma_{w}\right)\left(w_{t}^{*}\right)^{1-\epsilon_{w}}+\gamma_{w}\left(w_{t-1} \Pi_{t}^{\gamma_{i n d, w}-1}\right)^{1-\epsilon_{w}}
$$

Real wages depend directly on the responses of both inflation and nominal wage inflation in the following way

$$
w_{t}=\frac{\Pi_{t}^{W}}{\Pi_{t}} w_{t-1}
$$

This is an identity that must always hold.

Wage dispersion is measured by the following expression

$$
\Delta_{t}^{W}=\left(1-\gamma_{w}\right) \tilde{w}_{t}^{-\epsilon}+\gamma_{w}\left(\frac{\prod_{t}^{\gamma_{i n d, w}}}{\prod_{t}^{W}}\right)^{-\epsilon_{w}} \Delta_{t-1}^{W}
$$




\subsection{Financial Intermediaries}

In this subsection, the partial equilibrium banking model is translated into the general equilibrium model. As in Gertler and Kiyotaki (2010) and Gertler and Karadi (2011), banks act as financial intermediaries, providing corporate loans by receiving deposits from saving households. Banks make profits based on the expected difference between the lending rate and the deposit rate. The existing agency problem between savers and banks introduces a counter-cyclical credit spread.

Again, banks' lending to non-financial firms, $Q_{t} S_{j, t}$, is financed by their net worth $N_{j, t}$ and the deposits received from households $D_{j, t}$. The balance sheet of financial intermediaries can be written as

$$
Q_{t} S_{j, t}=N_{j, t}+D_{j, t+1}
$$

$Q_{t}$ denotes the relative price of the banks' assets. ${ }^{7}$ As before in the partial equilibrium, bankers' net worth follows a law of motion

$$
N_{j, t+1}=\left(R_{t+1}^{k}-R_{t+1}\right) Q_{t} S_{j, t}+R_{t+1} N_{j, t},
$$

with $R_{t+1}^{k}-R_{t+1}$ being the credit spread between corporate loans rate and deposit rate. No financial intermediary would finance assets yielding negative earnings. Hence the following inequality for discounted return on assets must hold

$$
E_{t} \beta^{i} \Lambda_{t, t+1+i}\left(R_{t+1+i}^{k}-R_{t+1+i}\right) \geq 0, i \geq 0 .
$$

The agency problem in the general equilibrium model is given by

$$
V_{j, t} \geq \lambda Q_{t} S_{j, t}
$$

\footnotetext{
${ }^{7}$ In this model, the terms assets and loans are mutually interchangeable. As in Gertler and Karadi (2011), corporate loans act simultaneously as assets on banks' balance sheets.
} 
Each period, a banker can divert a constant fraction $\lambda$ of assets $Q_{t} S_{j, t}$ to transfer the profits back to her own household. The bank operates as long as the expected terminal wealth is larger than, or equal to, the divertible share. The corresponding financial intermediary managed by this banker goes bankrupt and households recover only the fraction $1-\lambda$ of banks' assets. Thus, households will limit the supply of deposits and, in turn, banks' funds are constrained. Financial intermediaries maximize then their terminal expected wealth

$$
V_{j t}=\max E_{t} \sum_{i=1}^{\infty}(1-\theta) \theta^{i} \beta^{i+1} \Lambda_{t, t+1+i}
$$

such that the balance sheet constraint (22), the law of motion of net worth (23), and the incentive constraint (25) are fulfilled. Whereas $\theta$ is the probability that a banker can continue her work. In each period bankers quit with a constant probability $1-\theta$ to ensure that the balance sheet constraint always binds.

\subsubsection{Banks' optimality conditions}

Following Gertler and Kiyotaki (2010), I guess and verify a linear value function in assets and net worth

$$
V_{j, t}=\nu_{t} Q_{t} S_{j, t}+\eta_{t} N_{j, t}
$$

The maximization problem provides the solution for aggregate demand for assets

$$
Q_{t} S_{t}=\phi_{t} N_{t}
$$

with $\phi_{t}=\frac{\eta_{t}}{\lambda-\nu_{t}}$ denoting the leverage ratio of banks. Further, it provides the recursive solution for the coefficients of the value function

$$
\begin{aligned}
& \nu_{t}=E_{t}\left[(1-\theta) \beta \Lambda_{t, t+1}\left(R_{t+1}^{k}-R_{t+1}\right)+\beta \Lambda_{t, t+1} \theta x_{t, t+1} \nu_{t+1}\right] \\
& \eta_{t}=E_{t}\left[(1-\theta)+\beta \Lambda_{t, t+1} \theta z_{t, t+1} \eta_{t+1}\right]
\end{aligned}
$$


where $z_{t, t+1}$ is the growth rate in wealth and $x_{t, t+1}$ is the growth rate in assets. Both are given by these two expression

$$
\begin{aligned}
& z_{t, t+1}=\frac{N_{j, t+1}}{N_{j, t}}=\left(R_{t+1}^{k}-R_{t+1}\right) \phi_{t}+R_{t+1} \\
& x_{t, t+1}=\frac{Q_{t+1} S_{j, t+2}}{Q_{t} S_{j, t+1}}=\frac{\phi_{t+1}}{\phi_{t}} \frac{N_{j, t+1}}{N_{j, t}}=\frac{\phi_{t+1}}{\phi_{t}} z_{t, t+1} .
\end{aligned}
$$

Therefore, neither the growth rate of assets $x_{t, t+1}$ nor the growth rate of net worth $z_{t, t+1}$ depends on firm-specific factors. As one can see, equation (1) of the two periods partial equilibrium model is a special case of the more general equation (28).

Aggregate net wealth is the sum of wealth of existing financial intermediaries and newly founded banks

$$
N_{t}=N_{e t}+N_{n t}
$$

The aggregate net worth of existing banks follows the law of motion from equation (23), which can be written as

$$
N_{e t}=\theta\left[\left(R_{t}^{k}-R_{t}\right) \phi_{t-1}+R_{t}\right] N_{t-1}
$$

Each period, households obtain a total of $(1-\theta) Q_{t} S_{t-1}$ from dissolved financial intermediaries. A fraction $\omega /(1-\theta)$ will be used to provide start-up funds to new bankers. Net worth of new banks is thus given by

$$
N_{n t}=\omega Q_{t} S_{t-1}
$$

The equations (28)-(35) describe the aggregate financial sector. 


\subsection{Intermediate Goods-Producing Firms}

Perfectly competitive firms produce intermediate goods by using labor hours $L_{t}$ and capital $K_{t}$. Production is specified by a Cobb-Douglas function

$$
Y_{t}=A_{t}\left(\xi_{t} K_{t}\right)^{\alpha} L_{t}^{1-\alpha}
$$

The level of technology $A_{t}$ and the quality of capital $\xi_{t}$ both follow an auto-regressive process of order one. The produced intermediate goods are sold to final retailers for the relative price $P_{t}^{m}$. Intermediate firms are paying the real wage $w_{t}$ for labor hours and acquire capital from capital producers. It takes one period until new capital becomes active. After production, at the end of each period, intermediate firms can

sell depreciated capital at price $Q_{t}$ and acquire new capital $K_{t+1}$. New capital is financed by funds from financial intermediaries. Non-financial firms issue claims $S_{t}$ with price $Q_{t}$ such that the value of capital $Q_{t} K_{t+1}$ equals the value of claims $Q_{t} S_{t}$

$$
Q_{t} K_{t+1}=Q_{t} S_{t}
$$

The resulting first order conditions are defined in the following. Labor demand in the economy is described by

$$
(1-\alpha) \frac{Y_{t}}{L_{t}}=\frac{w_{t}}{P_{t}^{m}}
$$

The second equation is derived by the optimal choice of capital, given as

$$
R_{t+1}^{k}=\frac{\xi_{t+1}\left(P_{t+1}^{m} \alpha \frac{Y_{t+1}}{\xi_{t+1} K_{t+1}}+Q_{t+1}-\delta\right)}{Q_{t}}
$$

This equation defines the return financial intermediaries earn by financing capital acquirement. The depreciation rate of capital, $\delta$, is constant. 


\subsection{Capital Producing Firms}

Competitive capital producers, owned by households, create new capital and repair depreciated capital bought from the intermediate goods-producers. Net investment $I_{n t}$ is defined as the difference between gross investment $I_{t}$ and depreciated capital $\delta \xi_{t} K_{t}$

$$
I_{n t}=I_{t}-\delta \xi_{t} K_{t}
$$

By choosing net investment $I_{n t}$, firms maximize their profits

$$
\max _{I_{n t}} E_{t} \sum_{\tau=t}^{\infty} \beta^{T-t} \Lambda_{t, \tau}\left\{\left(Q_{\tau}-1\right) I_{n \tau}-f\left(\frac{I_{n \tau}+I_{s s}}{I_{n \tau-1}+I_{s s}}\right)\left(I_{n \tau}+I_{s s}\right)\right\} .
$$

The steady state value of gross investment is given by $I_{s s} \cdot f(\cdot)$ denotes the functional form of investment adjustment costs. Following Christiano et al. (2005) the functional form is given by

$$
\frac{\eta_{i}}{2}\left(\frac{I_{t}-\delta \xi_{t} K_{t}+I_{s s}}{I_{n t-1}+I_{s s}}-1\right)^{2}
$$

with $\eta_{i}$ measuring the inverse elasticity of net investments to changes in the price of capital. The first order condition defines the price of capital as follows

$$
Q_{t}=1+f_{t}(\cdot)+f_{t}^{\prime}(\cdot) \frac{I_{n t}+I_{S S}}{I_{n t-1}+I_{S S}}-\beta E_{t}\left\{\Lambda_{t, t+1} f_{t+1}^{\prime}(\cdot)\left(\frac{I_{n t+1}+I_{S S}}{I_{n t}+I_{S S}}\right)^{2}\right\} .
$$

\subsection{Retail Firms}

Retail firms combine the intermediate goods $Y_{f t}$ and sell the final goods to consumers. Price setting for final goods is similar to the wage setting framework described before. Final output is given by the Dixit-Stiglitz aggregator

$$
Y_{t}=\left(\int_{0}^{1} Y_{f t}^{\frac{\epsilon-1}{\epsilon}} d f\right)^{\frac{\epsilon}{\epsilon-1}}
$$


The elasticity of substitution between two differentiated goods is expressed by the parameter $\epsilon$. Through consumers' cost minimization of purchasing a certain consumption bundle, $C_{t}$, the aggregate price level is defined as

$$
P_{t}=\left(\int_{0}^{1} P_{f t}^{1-\epsilon} d f\right)^{\frac{1}{1-\epsilon}}
$$

The demand for goods of firm $f$ can be written as the following demand constraint

$$
Y_{f t}=\left(\frac{P_{f t}}{P_{t}}\right)^{-\epsilon} Y_{t}
$$

Again nominal price stickiness is introduced by a Calvo mechanism. Every period a fraction $\gamma_{p}$ of firms must keep their prices constant. Firms that do not change prices will index their prices to lagged inflation. Retail firms are maximizing lifetime discounted expected profit according to the following optimization problem

$$
\max _{P_{t}^{*}} E_{t} \sum_{i=0}^{\infty} \gamma_{p}^{i} \beta^{i} \Lambda_{t, t+i}\left[\frac{P_{t}^{*}}{P_{t+i}} \prod_{k=1}^{i}\left(1+\pi_{t+k-1}\right)^{\gamma_{i n d, p}}-P_{t+i}^{m}\right] Y_{f t+i}
$$

such that the demand constraint is fulfilled. $P_{t}^{*}$ is the newly set optimal price. Inflation occurs because a fraction $1-\gamma_{p}$ of firms readjust their prices inducing $\Pi_{t}^{*}$ inflation and the other fraction of firms $\gamma_{p}$ keep their prices indexed to inflation. Again, one can derive the price dispersion term as

$$
\Delta_{t}^{P}=\left(1-\gamma_{p}\right){\tilde{p_{t}^{*}}}^{-\epsilon}+\gamma_{p}\left(\frac{\Pi_{t}^{\gamma_{\text {ind,p }}}}{\Pi_{t}}\right)^{-\epsilon} \Delta_{t-1}^{P}
$$

\subsection{Economy-wide Resource Constraint and Government Policy}

The economy is modeled as a closed economy including capital and adjustment costs in investments. Aggregate output $Y_{t}$ consists of aggregate consumption $C_{t}$, investments for new capital $I_{t}$, the adjustment costs of investments and government expenditures $G_{t}$, where the output level is corrected by the price dispersion $\Delta_{t}^{p}$, and 
wage dispersion $\Delta_{t}^{w}$ terms

$$
Y_{t}=\Delta_{t}^{p} \Delta_{t}^{w}\left(C_{t}+I_{t}+f\left(\frac{I_{n, t}+I_{S S}}{I_{n, t-1}+I_{S S}}\right)\left(I_{n, t}-I_{S S}\right)+G_{t}\right)
$$

Government expenditures $G_{t}$ are described by an auto-regressive process. In equilibrium, the Fisher equation for nominal interest rate $i_{t}$ has to hold

$$
i_{t}=E_{t}\left[R_{t+1} \Pi_{t+1}\right] .
$$

The central bank's nominal interest rate rule is given by the following Taylor rule stabilizing price inflation, wage inflation, and output gap. ${ }^{8}$

$$
i_{t}=\left[\bar{i} \Pi_{t}^{\kappa_{\pi}}\left(\Pi_{t}^{W}\right)^{\kappa_{\pi_{w}}}\left(\frac{Y_{t}}{Y_{t}^{*}}\right)^{\kappa_{y}}\right]^{1-\rho} i_{t-1}^{\rho} \epsilon_{m, t} .
$$

$\bar{i}$ is the steady state level of the nominal interest rate. The price inflation coefficient of the Taylor rule is defined as $\kappa_{\pi}$ and the coefficient on wage inflation is given by $\kappa_{\pi_{w}} . \kappa_{y}$ is the coefficient of stabilizing output gap. Interest rate smoothing is governed by parameter $\rho$. The output gap is defined as the difference to the level of output in absence of nominal frictions.

\subsection{Measure of welfare}

The policy maker's objective function is given by the lifetime utility of households

$$
\mathcal{W}_{t}=E_{t} \sum_{i=0}^{\infty} \beta^{i}\left[\ln \left(C_{t+i}-h C_{t+i-1}\right)-\frac{\chi}{1+\varphi} L_{t+i}^{1+\varphi}\right]
$$

Due to identical steady states under the considered monetary policies, for the welfare measurement, I take second-order effects into account. The relative welfare costs of implementing a certain policy is evaluating by the conditional expected lifetime

\footnotetext{
${ }^{8}$ Later I test the robustness of the welfare effects of monetary policy by including additional financial variables. Faia and Monacelli (2007) augment an otherwise standard Taylor rule with a response to asset prices and demonstrate that such an augmentation fails to replicate optimal monetary policy. However, they solely focus on technology shocks.
} 
utility at period zero, following Schmitt-Grohé and Uribe (2007). For all policies the economy starts at the same deterministic steady state. The welfare comparison accounts for the transition from the identical deterministic steady state to the policy specific stochastic steady state. Defining the conditional expected lifetime utility of reference policy $r$, the time-less Ramsey-optimal policy under commitment, by

$$
\mathcal{W}_{0}^{r}=E_{0} \sum_{t=0}^{\infty} \beta^{t} U\left(C_{t}^{r}, L_{t}^{r}\right)
$$

and lifetime utility of a second policy $a$ by

$$
\mathcal{W}_{0}^{a}=E_{0} \sum_{t=0}^{\infty} \beta^{t} U\left(C_{t}^{a}, L_{t}^{a}\right)
$$

One can now measure the welfare costs of policy $a$ 's implementation by the fraction of regime $r$ 's consumption a household gives up to be equally well off. Thus, regime $a$ 's conditional welfare can be expressed in terms of the contingent plans for consumption and labor hours under the reference policy

$$
\mathcal{W}_{0}^{b}=E_{0} \sum_{t=0}^{\infty} \beta^{t} U\left(\left(1-\lambda_{w c}\right) C_{t}^{r}, L_{t}^{r}\right)
$$

where $\lambda_{w c}$ denotes the welfare costs of adopting policy $a$ instead of policy $r$.

Using the definition of the utility function and rearranging the expression above provides us with a relative measure for welfare costs in percentage points

$$
\lambda_{w c} * 100=\left(1-\exp \left(\left(\mathcal{W}_{0}^{a}-\mathcal{W}_{0}^{r}\right)(1-\beta)\right)\right) * 100 .
$$

As the reference point, I compute the Ramsey-optimal policy under commitment in the constrained model economy, that maximizes households' expected lifetime utility. The Ramsey-optimal policy is computed from a timeless perspective. 


\section{Empirical Validation}

In the model one period is set to one quarter of a year. The calibration of this model is empirically validated by following the approach of Mendicino et al. (2018). In their paper they calibrate the model parameters to match first and second data moments.

The calibration of the model parameters is done in two steps. First, the set of parameters is split into different groups. The parameters that affect the deterministic steady state $\Theta_{S S}$ and the parameters that do not affect the deterministic steady state $\Theta_{N S S}$. The first group of parameters are calibrated by minimizing a loss function with equal weights on the distance between first data moments and model implied first moments (steady state values). Second, I add the remaining parameters $\Theta_{N S S}$ to the estimation and repeat the exercise, this time using second order moments. Again, the parameters are found by minimizing the distance between model implied second moments and the data moments.

Within step one, one parameter has a direct data equivalent, the share of government expenditure $g_{s s}$ and, thus, is directly set to its corresponding empiric value.

\subsection{Data series}

The model is validated using macro data series for the United States, starting from 1985Q1 until 2018Q4. Therefore, I explicitly take both the Great Moderation and the Great Recession into account. ${ }^{9}$ All data moments are in real terms and per capita. Nominal time series are deflated by using a GDP deflator with index year 2012. In order to compute per capita series, each series is divided by total employment. Second moments are based on the growth rates of per capita variables. All data series are acquired from FRED, Federal Reserve Bank of St. Louis. A more detailed description of the data series is in appendix B.

\footnotetext{
${ }^{9}$ As a robustness check I cut the sample, using only the last 20 years, starting from 1999Q1. The results of the first moments matching barely differ. The only difference is a slightly higher inverse Frisch labor elasticicy $\varphi$ and a slightly higher intertemporal labor elasticity $\epsilon_{w}$.
} 


\subsection{Empirical results}

A few parameters were first preset to common values from the literature. The preset values of these parameters are found in table A2 in the appendix. These are the capital share, the households' discount rate, and the capital depreciation rate. Disutility from labor is assumed to be equal to one. The Taylor rule parameters are set to the same values as in Gertler and Karadi (2011). Later I vary the policy parameters when analyzing the welfare effects of monetary policy.

\subsubsection{First moments matching}

The first moments matched are summarized in table 2. The targeted data moments are well matched with a total difference of 0.514 between model implied steady state values and the empirical values. The model fits especially well consumption, real wages, and investment. The banking related moments bank leverage, credit spread, and return on equity deviate from their targets to some degree.

The targets above were compared with alternative targets including bank net worth and loans to non-financial corporations to ensure the parameters provide the best possible fit to the data. For the alternative targets, the total distance was significantly higher. One reason is that the model cannot simultaneously match leverage and loan data. Since firm loans are the only asset in the model, banks in the model must issue an amount of loans relative to output that is far above the data target given a reasonably level of leverage. Including net worth does not improve the fit either. The level of leverage needed to fit net worth over output would be unreasonable high. ${ }^{10}$ The same mechanism explains why the financial moments in table 2 are not perfectly matched. Return on equity and the credit spread can both perfectly matched for a lower level of leverage, e.g. by using firm leverage as the new target (with a value of about 3.9). ${ }^{11}$ However, this has two drawbacks. First, the implied share of divertable funds must be about $55 \%$; thus relatively high.

\footnotetext{
${ }^{10} \mathrm{~A}$ leverage level of about 20 would be needed. Furthermore the model reaches regions of indeterminacy for such high values.

${ }^{11}$ Gertler and Karadi (2011) use for their own calibration a leverage of 4 as a reference point.
} 


\begin{tabular}{|c|c|c|c|}
\hline Description & Moment & Model & $\overline{\text { Data }}$ \\
\hline \multicolumn{4}{|c|}{ First moments } \\
\hline Consumption / GDP & $\frac{C}{Y}$ & 0.6499 & 0.6732 \\
\hline Business investment / GDP & $\frac{Y}{Y}$ & 0.1312 & 0.1322 \\
\hline Real wage / GDP & $\frac{w}{Y}$ & 0.4529 & 0.4529 \\
\hline Bank leverage & $\phi$ & 5.2379 & 7.6313 \\
\hline Return on equity & $\left(1+\left(R^{k}-R\right) \times 400\right) \phi$ & 13.2991 & 9.1281 \\
\hline Credit spread & $R^{k}-R$ & 0.0038 & 0.0050 \\
\hline Government expenditure / GDP & $\frac{G}{Y}$ & 0.2189 & 0.2189 \\
\hline Distance first moments: & & \multicolumn{2}{|c|}{0.5140} \\
\hline \multicolumn{4}{|c|}{ Second moments } \\
\hline Consumption / GDP & $\frac{\sigma(C)}{\sigma(Y)}$ & 0.8324 & 0.9059 \\
\hline Investment / GDP & $\frac{\sigma(I)}{\sigma(Y)}$ & 3.8602 & 6.2745 \\
\hline Hours / GDP & $\frac{\sigma(L)}{\sigma(Y)}$ & 1.6382 & 0.8772 \\
\hline Wage inflation / GDP & $\frac{\sigma\left(\Pi^{W}\right)}{\sigma(Y)}$ & 57.1549 & 150.0779 \\
\hline Leverage / GDP & $\frac{\sigma(\phi)}{\sigma(Y)}$ & 4.2407 & 2.7685 \\
\hline Government expenditure / GDP & $\frac{\sigma(G)}{\sigma(Y)}$ & 2.0180 & 1.3939 \\
\hline Credit spread / GDP & $\frac{\sigma\left(R^{k}-R\right)}{\sigma(Y)}$ & 76.2134 & 66.2511 \\
\hline Bank net worth / GDP & $\frac{\sigma(N)}{\sigma(Y)}$ & 5.3162 & 2.9774 \\
\hline NFC loans / GDP & $\frac{\sigma(S)}{\sigma(Y)}$ & 1.9442 & 3.7007 \\
\hline Inflation & $\sigma(\Pi)$ & 127.1347 & 156.6106 \\
\hline Policy rate & $\sigma(i)$ & 64.4629 & 270.6144 \\
\hline Consumption / GDP & $\operatorname{Corr}(C, Y)$ & 0.6030 & 0.7384 \\
\hline Investment / GDP & $\operatorname{Corr}(I, Y)$ & 0.7695 & 0.6436 \\
\hline Hours / GDP & $\operatorname{Corr}(L, Y)$ & 0.3865 & 0.7437 \\
\hline Wage inflation / GDP & $\operatorname{Corr}\left(\Pi^{W}, Y\right)$ & 0.0534 & -0.0338 \\
\hline Leverage / GDP & $\operatorname{Corr}(\phi, Y)$ & -0.0581 & -0.0672 \\
\hline Government expenditure / GDP & $\operatorname{Corr}(G, Y)$ & 0.6430 & 0.2909 \\
\hline Credit spread / GDP & $\operatorname{Corr}\left(R^{k}-R, Y\right)$ & -0.2755 & -0.1599 \\
\hline Bank net worth / GDP & $\operatorname{Corr}(N, Y)$ & 0.1023 & 0.0311 \\
\hline NFC loans / GDP & $\operatorname{Corr}(S, Y)$ & 0.0494 & 0.0457 \\
\hline Inflation & $\operatorname{Corr}(\Pi, Y)$ & -0.0098 & 0.0178 \\
\hline Policy rate & $\operatorname{Corr}(i, Y)$ & -0.2564 & -0.0105 \\
\hline Total distance: & & 21. & 907 \\
\hline
\end{tabular}

Table 2: The table summarizes the first moments matched. The model parameters are set such that the distance between model-implied steady state values and data moments is minimized.

Second, a leverage of four would imply a level of equity capital of $25 \%$, which would be way above any discussed bank capital requirement levels. I regard the reported calibration below as a middle ground for the model.

After calibrating those parameters that affect the steady state by matching first 


\begin{tabular}{lcclll}
\hline \hline Description & \multicolumn{1}{c}{ Value } & Description & Value \\
\hline Direct match & & & & & \\
Gov. expenditure to GDP & $g_{s s}$ & 0.2189 & & & \\
\multicolumn{5}{c}{ First and second } & moments distance minimization \\
Elast. of substitution & $\epsilon$ & 1.6141 & Transfer to new bankers & $\omega$ & 0.0024 \\
Adjustment costs parameter & $\eta_{i}$ & 5.5094 & Survival rate bankers & $\theta$ & 0.9585 \\
Habits & $h$ & 0.5296 & Intratemp. elast. of labor & $\epsilon_{w}$ & 1.1018 \\
Share of divertable assets & $\lambda$ & 0.3612 & Inverse Frisch elasticity & $\varphi$ & 5.1255 \\
\hline Shocks & & & & & \\
\hline Std. dev. technology & $\sigma_{a}$ & 0.8905 & Std. dev. price markup & $\sigma_{\mu_{p}}$ & 0.5181 \\
Std. dev. preference & $\sigma_{c}$ & 0.5128 & Std. dev. wage markup & $\sigma_{\mu_{w}}$ & 0.5001 \\
Std. dev. inv. elasticity & $\sigma_{\chi}$ & 0.4078 & Std. dev. wealth & $\sigma_{w}$ & 0.1967 \\
Std. dev. gov. expenditure & $\sigma_{g}$ & 0.2455 & Std. dev. monetary policy & $\sigma_{m}$ & 0.0337 \\
Std. dev. capital quality & $\sigma_{k}$ & 0.0193 & Persist. capital quality & $\rho_{k}$ & 0.2956 \\
Persist. technology & $\rho_{a}$ & 0.8302 & Persist. price markup & $\rho_{\mu_{p}}$ & 0.4973 \\
Persist. preference & $\rho_{c}$ & 0.5078 & Persist. wage markup & $\rho_{\mu_{w}}$ & 0.4940 \\
Persist. inv. elasticity & $\rho_{\chi}$ & 0.8137 & Persist. wealth & $\rho_{w}$ & 0.7024 \\
Persist. gov. expenditure & $\rho_{g}$ & 0.9884 & & & \\
\hline \hline
\end{tabular}

Table 3: Parameters found by first and second moment matching.

moments, I continue with a second step that matches both first and second moments. Again I calibrate those parameters that affect the steady state, but this time together with the parameters of the shock process. ${ }^{12}$

\subsubsection{Second moments matching}

The remaining rows in table 2 report the matched second moments. The model gets most of the correlations between gross domestic product and the other macro and financial aggregates right. Exceptions are the correlation between hours and GDP as well as government expenditure and GDP. The model assumes weaker pro-cyclical hours worked and a stronger co-movement between government expenditures and GDP than observed in the data.

The model has further troubles matching the magnitude of the standard deviations in inflation, wage inflation, and policy rates, which are all more volatile in the data. The mismatch between those three aggregates mainly explains the resulting larger total distance between all moments within the minimization routine.

The values of the calibrated parameters are reported in table 3. The credit spread,

\footnotetext{
${ }^{12}$ This two-step approach guarantees better convergence to the global minimum distance .
} 
return on equity, and leverage can be matched by varying the three financial parameters. The parameter of the investment adjustment costs $\eta_{i}$ helps to pin down investment to GDP. Habits, the inverse Frisch labor elasticity, and the different elasticities of substitutions can determine the consumption to GDP and the real wages to GDP ratios. The estimated probability that a banker will not exit the financial intermediary is given by $\theta=0.9585$. Thus, with a probability of about $4 \%$, each period a bank will shut down and transfer the fraction $(1-\theta) Q_{t} S_{t-1}$ of intermediated assets back to the households. This revenue is then used by households to give a start-up fund, represented by the fraction $\frac{\omega}{1-\theta}$, to newly entering banks, with $\omega=0.0024$. The value of $\lambda$ of 0.361 implies that, in equilibrium, bankers can divert $36.1 \%$ of their assets. The inverse Frisch labor elasticity is, with a value of 5.17, still within the range of estimated values from the literature. The elasticity of substitution between different kinds of goods and the elasticity of substitution between types of labor are around a value of 2.63 and 10.35 .

The shocks with the highest standard deviation are technology shocks, household preference shocks and investment elasticity shocks.

\section{The credit spread and wages in general equilibrium}

In this section, I investigate the interaction between wage setting, good-producing firms' factor demand, and bank profitability in the general equilibrium model with a financial accelerator. Building on the results in section 3.2, the question emerges whether the substitution effect of wage setting or the scale effect play the more important role in the general equilibrium. For the first part of the analysis, I assume that nominal wages are flexible for the time being.

In a standard textbook new-Keynesian DSGE model with sticky prices, flexible nominal wages, and a frictionless financial market, several studies in the literature, including Erceg et al. (2000) and Galí (2008) show that central banks should only target inflation to automatically close the output gap, a phenomenon labelled divine coincidence. Nominal wages in these textbook new-Keynesian DSGE models should 
be able to freely move, such that real wages can sufficiently adjust to their natural level.

Thus, one would expect, in banking models under sticky prices but flexible nominal wages, that good-producing firms benefit from falling nominal wages after a contractionary financial shock. In this line of argument, a natural real wage level and a central bank that stabilizes inflation eventually brings output closer to its natural level and, thus, also has a positive impact on loan demand. ${ }^{13}$ Any policy that prevents nominal wages from sufficiently falling, would bear some output costs. This channel is labelled the scale effect channel of nominal wage setting in section 3.2 .

The results in 3.2 in partial equilibrium suggest, however, that higher real wages can also have a substitution effect on capital demand, increasing the demand for loans in relative terms during a recession that, in turn, stabilizes banks' net worth.

In the following, I investigate three different scenarios to disentangle both channels and to see which one remains relevant in the fully-fledged banking model. To this end, I define a scenario (A) under which a central bank follows a Taylor rule stabilizing only inflation with $\kappa_{\pi}=1.75$, a scenario (B) under which a central bank stabilizes wage inflation only, with $\kappa_{\pi_{w}}=1.75$, this resembles the exercise in column (II) in table 1 with the difference of an increase not a decrease in wages. Finally, scenario $(\mathrm{C})$ tries to shut off the positive effects of the substitution effect on the financial accelerator, by stabilizing wage inflation as in (B) but holding the price of assets at the imposed levels of scenario (A). As in the partial equilibrium case, I only consider a one standard deviation capital quality shock, which resembles a financial credit supply shock.

Table 4 summarizes the results for all three scenarios in terms of volatility of output, consumption, price of assets, and labor. The last row is a measure for unconditional welfare costs in consumption equivalences. See section and equation

\footnotetext{
${ }^{13}$ However, in this model with financial frictions and endogenous capital accumulation, monetary policy also induces endogenous cost push effects, the so called cost channel of monetary policy, as elaborated by e.g. Demirel (2009), that reduces the effectiveness of inflation targeting.
} 


\begin{tabular}{c|ccc}
\hline \hline & Scenario A & Scenario B & Scenario C \\
\hline$\sigma(Y)$ & 0.0053 & 0.0049 & 0.0053 \\
$\sigma(C)$ & 0.0043 & 0.0042 & 0.0050 \\
$\sigma(Q)$ & 0.0023 & 0.0014 & 0.0023 \\
$\sigma(L)$ & 0.00020 & 0.00015 & 0.00022 \\
$\lambda_{w c}$ & 0.0028 & - & 0.0032 \\
\hline \hline
\end{tabular}

Table 4: The table summarizes the volatility in output, consumption, price of capital, labor, and welfare costs in consumption equivalence relative to scenario B, given a negative standard deviation capital quality shock under sticky prices but flexible nominal wages. Under scenario (A) a central bank follows a Taylor rule stabilizing only inflation, under scenario (B) a central bank stabilizes wage inflation only. The scenario (C) isolates the scale effect of nominal wages, by stabilizing wage inflation as in (B) but holding the price of assets at the imposed levels of scenario $(\mathrm{A})$.

(52) for details on welfare computation. Scenario B yields the highest welfare, which is why all welfare costs are calculated relative to scenario B.

Scenario B performs better in terms of stabilizing all reported variables and yields higher welfare compared to A. Although nominal wages are flexible, there exist some benefits of stabilizing wages. By having a look on the results of scenario C, I can confirm that wage stabilization depresses firms output via the scale effect channel of nominal wages and that it indeed is the substitution channel's effects on the financial accelerator that boosts loan demand. Once the benefits of the substitution channel on banks' profits are shut down, monetary policy is better off by targeting inflation.

Figure 1 summarizes visually the results discussed above by reporting for all three scenarios the impulse responses of output, welfare, and price of capital given flexible nominal wages.

This section shows that two channels play a relevant role when it comes to the effects of households wage setting on financial intermediation and aggregate output. The first channel (i), labelled the scale effect channel of nominal wages, suggests that nominal wages that are prevented from falling sufficiently during a recession, depress firms' profits, output, and also loan demand and bank profits. The second channel (ii), labelled the substitution effect channel, implies that firms substitute away from labor towards capital under higher nominal wage levels, that increases capital demand, the price of capital, and, eventually, also bank profits. The results indicate that in a model with frictional financial intermediation in which capital 

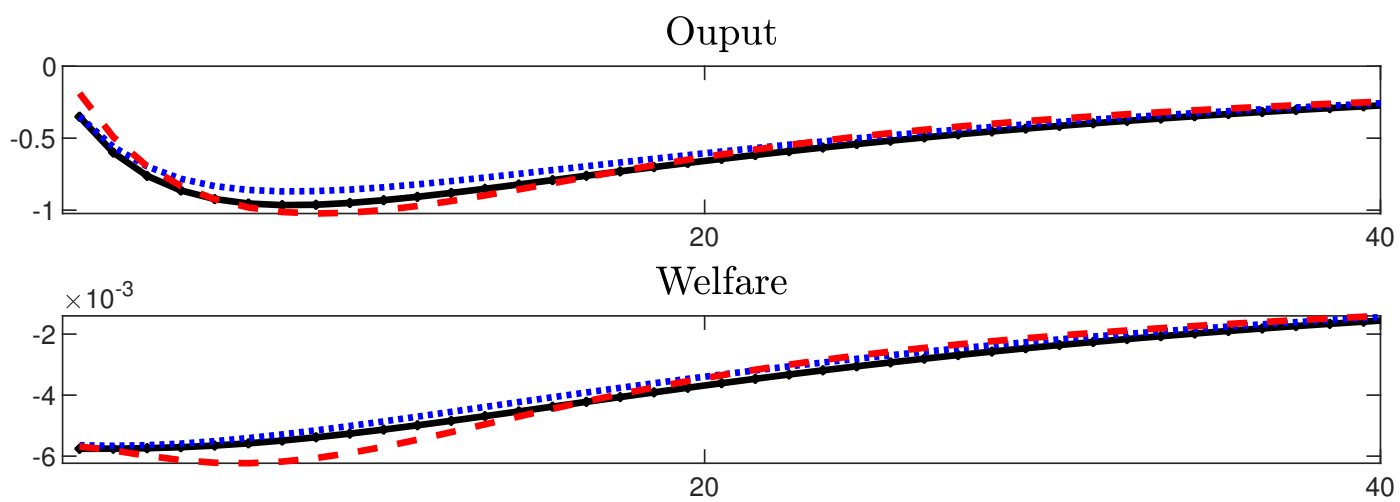

Price of capital

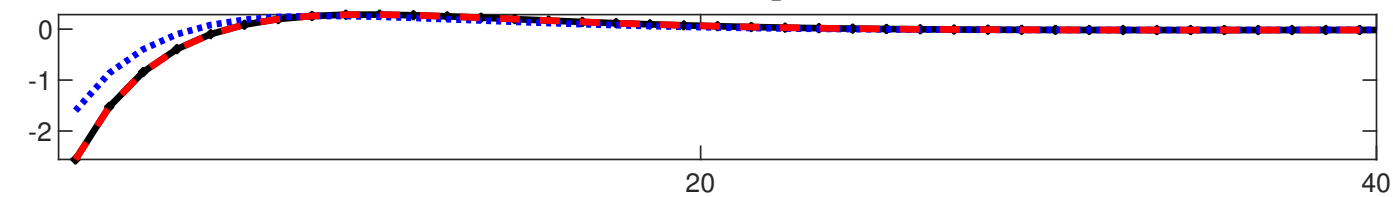

A: inflation targeting ........ B: wage targeting = - - C: wage targeting w/ Q at (A) levels

Figure 1: Impulse responses to a negative one standard deviation shock to the quality of capital under sticky prices but flexible wages. Under scenario (A), a central bank follows a Taylor rule stabilizing only inflation, while under scenario (B), a central bank only stabilizes wage inflation. Scenario (C) isolates the scale effect of nominal wages, by stabilizing wage inflation as in (B) but holding the price of assets at the imposed levels of scenario $(\mathrm{A})$.

acts as a collateralized asset, the second channel dominates due to the effects of the financial accelerator mechanism on aggregate output.

The beneficial effects of wage inflation targeting even under flexible nominal wages, raise concerns regarding what optimal monetary policy looks like in such a setting. Thus, in the next section I focus on optimal monetary policy.

\section{Optimal Monetary Policy}

In the following, I introduce a welfare measure and compare a variety of policy rules with the derived time-less Ramsey-optimal policy under commitment. The welfare computations are conducted both under the benchmark calibration of sticky prices and sticky wages as well as under the simplified scenario described in section 6 with sticky prices but flexible nominal wages. I demonstrate that the trade-off between output gap and nominal wage inflation stabilization is only small, a finding that is based on the beneficial effects such policies have on the financial sector. The subsequent analysis further demonstrates that inflation stabilization implies 
significant welfare costs under both nominal rigidity scenarios.

\subsection{Optimal implementable simple rule under commitment}

The coefficients of the optimal-implementable simple rules are found by running a constraint optimization routine on the parameter space of policy parameters. The parameter vector yielding the highest conditional welfare is the one I denote as optimal simple rule. The search is constrained by a lower bound of zero for all parameters, except for inflation with a lower bound of one. ${ }^{14}$ Values for the weights on price inflation, wage inflation, and output gap are constrained by an upper bound of 50. For the interest rate indexation parameter, the search is bounded between zero and one. The simple monetary policy rule is defined by equation (51) as

$$
i_{t}=\left[\bar{i} \Pi_{t}^{\kappa_{\pi}}\left(\Pi_{t}^{W}\right)^{\kappa_{\pi_{w}}}\left(\frac{Y_{t}}{Y_{t}^{*}}\right)^{\kappa_{y}}\right]^{1-\rho} i_{t-1}^{\rho} \epsilon_{m, t} .
$$

The considered crisis scenarios are first a negative financial shock in form of an exogenous shock to the quality of capital. Second and third, a negative productivity shock and a household time-preference. Finally, I also consider a contractionary monetary policy shock.

The results are summarized in table 5. First, I discuss the results under the benchmark model with both nominal frictions present. In case of the financial shock, the capital quality shock, or the productivity shock, the optimal rule gives high weight on wage inflation and only minor weight on inflation stabilization or output gap. This changes for the two demand shocks, the contractionary monetary policy shock and the preference shock. Here the optimal response is to target a composite rule of inflation, wage inflation, and the output gap. Interest rate smoothing is not considered as optimal in any scenario in which wages are sticky.

Once the assumption of sticky wages is relaxed, the results for the financial shock

\footnotetext{
${ }^{14}$ For several policy parameters, the lower bound is hit. I do not allow for negative responses to inflation, wage inflation, or the output gap since central banks would have problems communicating the plausibility of such policies. To ensure determinacy the parameter on inflation cannot become smaller than one.
} 


\begin{tabular}{l|cccccc}
\hline \hline Capital Quality Shock & $\kappa_{\pi}$ & $\kappa_{\pi_{W}}$ & $\kappa_{y}$ & $\rho$ & OSR Welfare & Ramsey Welfare \\
\hline \hline$\gamma_{p}=0.75$ & 2.13 & 24.04 & 10.63 & 0.10 & -206.03 & -206.00 \\
$\gamma_{w}=0.75 \gamma_{p}=0.75$ & 1.10 & 49.89 & 2.01 & 0.00 & -206.01 & -205.89 \\
\hline Productivity Shock & $\kappa_{\pi}$ & $\kappa_{\pi_{W}}$ & $\kappa_{y}$ & $\rho$ & OSR Welfare & Ramsey Welfare \\
\hline \hline$\gamma_{p}=0.75$ & 26.99 & 5.65 & 0.01 & 0.99 & -206.20 & -206.19 \\
$\gamma_{w}=0.75 \gamma_{p}=0.75$ & 4.48 & 38.59 & 0.10 & 0.03 & -206.20 & -206.19 \\
\hline Preference Shock & $\kappa_{\pi}$ & $\kappa_{\pi_{W}}$ & $\kappa_{y}$ & $\rho$ & OSR Welfare & Ramsey Welfare \\
\hline \hline$\gamma_{p}=0.75$ & 47.35 & 6.40 & 0.37 & 0.85 & -206.22 & -206.19 \\
$\gamma_{w}=0.75 \gamma_{p}=0.75$ & 10.64 & 47.66 & 1.25 & 0.06 & -206.21 & -206.19 \\
\hline Monetary Shock & $\kappa_{\pi}$ & $\kappa_{\pi_{W}}$ & $\kappa_{y}$ & $\rho$ & OSR Welfare & Ramsey Welfare \\
\hline \hline$\gamma_{p}=0.75$ & 22.92 & 22.36 & 46.74 & 0.06 & -206.19 & -206.19 \\
$\gamma_{w}=0.75 \gamma_{p}=0.75$ & 1.15 & 0.15 & 47.39 & 0.06 & -206.19 & -206.19 \\
\hline \hline
\end{tabular}

Table 5: Coefficients of optimal simple rules under different model specifications.

support the findings of previous chapters. The evolution of nominal wages remains to play a prominent role under financial shocks. ${ }^{15}$ The optimal simple rule is a composite rule of wage inflation and output gap. Note that the capital quality shock is special in two aspects. First, it resembles a productivity shock on the capital input, combined with a financial component by hitting directly the asset side of banks' balance sheets. Second, the capital quality shock directly change the factor demand elasticities as pointed out by equation (8).

Inflation stabilization becomes a primary target under supply and demand shocks in which the policy maker still wants to put a non-neglectable focus on wage inflation.

\subsection{Comparison of alternative non-optimal simple rules}

The welfare costs for a variety of simple policy rules are reported in table 6 . The costs of adopting a policy are denoted in consumption equivalents relative to the Ramsey-optimal outcome. In this table, the results are only reported for a negative financial shock. The results for the productivity shock, preference shocks, and the monetary shock are found in the appendix. After a financial shock realizes, inflation targeting becomes costly in welfare terms. Under an inflation targeting rule with $\kappa_{\pi}=1.75$, households must be compensated by slightly more than $0.58 \%$ to be as good off as under the optimal rule regime. A central bank targeting solely wage

${ }^{15}$ The results are the same when, instead of a capital quality shock, a bank wealth shock is considered. 


\begin{tabular}{l|cc}
\hline \multicolumn{1}{c|}{ Capital quality shock } & $\gamma_{p}=0.75$ & $\gamma_{w}=0.75 \gamma_{p}=0.75$ \\
\hline Policy Rules & \multicolumn{2}{|c}{ Welfare Costs } \\
\hline$\kappa_{\pi}=1.75$ & 0.1222 & 0.5868 \\
$\kappa_{\pi_{W}}=1.75$ & 0.0460 & 0.1763 \\
$\kappa_{\pi}=1.75, \kappa_{y}=0.125$ & 0.1071 & 0.3508 \\
$\kappa_{\pi_{W}}=1.75, \kappa_{y}=0.125$ & 0.0446 & 0.1708 \\
$\kappa_{\pi}=1.75, \kappa_{\pi_{W}}=1.75$ & 0.0467 & 0.2113 \\
$\kappa_{\pi}=5$ & & \\
$\kappa_{\pi_{W}}=5$ & 0.0652 & 0.2776 \\
$\kappa_{y}=5$ & 0.0489 & 0.1525 \\
Optimal Simple Rule & 0.0553 & 0.1583 \\
\hline \hline
\end{tabular}

Table 6: Welfare costs of an one standard deviation capital quality shock for a selection of policy rules. The costs of welfare are expressed in consumption equivalents relative to the Ramsey-optimal monetary policy. In the first column nominal wages are perfectly flexible. In the second column both sticky wages and sticky prices are present.

inflation comes remarkably close to the optimal simple rule. Increasing the weight on inflation cannot compete in welfare terms with the wage inflation rules. ${ }^{16}$ As one can see under the stricter stabilization regimes (last 3 rows), the output gap rule yields similar results for welfare as the wage inflation rule.

The beneficial effects of wage inflation targeting are not a special case only caused by sticky wages under a capital quality shock. It also holds for other supply shocks, such as a negative productivity shock and an adverse shock to the investment elasticity. However, compared to the capital quality shock, this result is less pronounced. See tables A3 and A4 in the appendix.

Figure 2 compares four different policy scenarios: (1) the implementable optimal simple rule; (2) the constrained Ramsey-optimal policy; (3) a non-optimal simple inflation rule $\left(\kappa_{\pi}=1.75\right)$; and (4) a non-optimal simple wage inflation rule $\left(\kappa_{\pi_{w}}=\right.$ 1.75), under a one percent capital quality shock with both sticky prices and sticky wages.

The performance of the economy can be significantly improved under both the optimal simple rule and the wage inflation rule compared to the inflation targeting

\footnotetext{
${ }^{16}$ Indeed, even for extremely high values of $\kappa_{\pi}$, the welfare is lower than under the $\kappa_{\pi_{W}}=1.75$ rule.
} 

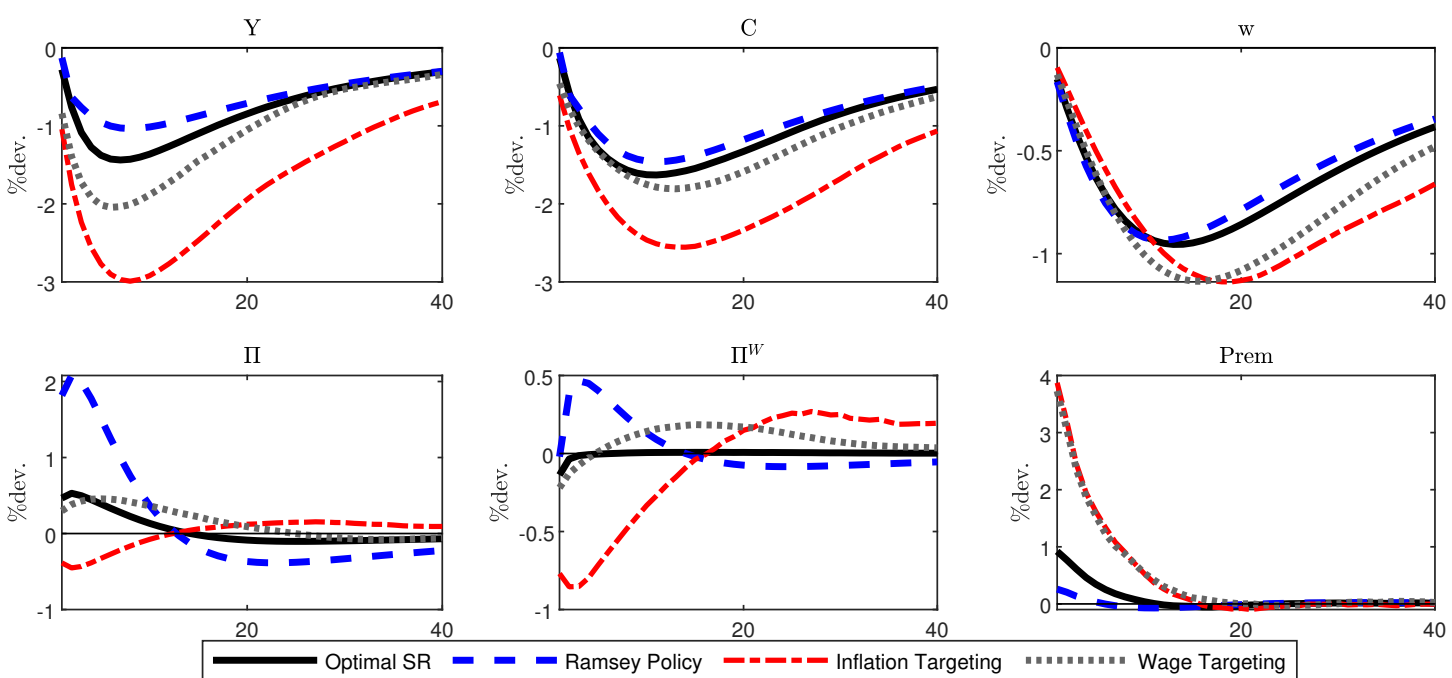

Figure 2: Impulse responses to an one percent capital quality shock under both sticky prices and sticky wages. The figure compares the implementable optimal simple rule from table 5 , a non-optimal simple wage inflation rule $\left(\kappa_{\pi_{w}}=1.75\right)$ and a simple inflation rule $\left(\kappa_{\pi}=1.75\right)$ with the constrained Ramsey-optimal policy rules.

rule. The initial response of output falls about $50 \%$ less. Wage inflation is close to zero under the optimal policy while a positive level of inflation is welfare optimal under the Ramsey policy. Preventing a drop in wage inflation affects the financial variables such as price of capital and the credit spread in a favorable fashion that mitigates the adverse effects of the financial accelerator. Further, by stabilizing wages, the frictions in nominal wage setting are eased, thus improving households' lifetime utility. The finding that some positive level of inflation helps achieving higher output and a higher level of employment is in line with Calvo et al. (2014). They find that in low-inflation regimes, unemployment is significantly higher after a banking crisis than in high-inflation regimes. The financial accelerator causes a stark amplification of the shock to capital quality compared to standard DSGE models without financial frictions. The stark increase in the spread propagates the large output and consumption drops, as made clear in Gertler and Karadi (2013). Monetary policy rules that are able to reduce the rise in the spread of interest rates are desirable from a welfare perspective.

In this chapter, the welfare effects of different monetary policy rules are evaluated. I show that even under the limiting case of flexible nominal wages, wage stabilization can be beneficial in welfare terms under financial shocks, such as cap- 
ital quality shocks and investment elasticity shocks. In these scenarios, the return on capital is predominately driven by expected marginal product of capital. Thus, the substitution effect channel dominates the scale effect channel.

\section{Robustness checks}

The first robustness exercise shows that (i) the found optimal simple rules in table 5 correspond indeed to the local maximum in welfare; and (ii) generalizes the results of table 6 by computing the welfare costs on a broader grid of parameter values. Further, I augment the Taylor rule with a term for the deviation of credit from its flexible price level. ${ }^{17}$

$$
i_{t}=\left[\bar{i} \Pi_{t}^{\kappa_{\pi}}\left(\Pi_{t}^{W}\right)^{\kappa_{\pi_{w}}}\left(\frac{Y_{t}}{Y_{t}^{*}}\right)^{\kappa_{y}}\left(\frac{S_{t}}{S_{t}^{*}}\right)^{\kappa_{x}}\right]^{1-\rho} i_{t-1}^{\rho} \epsilon_{m, t} .
$$

The second exercise in this section compares the stabilization effects of the optimal simple rule with a set of quadratic loss functions. The results indicate that a large trade-off between inflation and wage inflation exist whereas nearly no trade-off exist between closing the output gap, small credit spreads and minimizing wage inflation.

Finally, the subsection on the determinacy behavior of the model evaluates how well the monetary rules can rule out self-fulfilling sunspot shocks.

\subsection{Robustness of optimal implementable simple rules}

Figure 3 visualizes the findings from the welfare costs relative to the Ramsey policy, on a grid for the policy coefficients. In each plot, the inflation coefficient and one other policy coefficients are varied, the other remaining coefficients are set to zero. The high welfare costs of pure inflation targeting rules are clearly visible. Wage inflation targeting with zero weight on inflation and output gap targeting perform

\footnotetext{
${ }^{17}$ This follows a strand of literature arguing for augmenting Taylor rules with responses to financial variables (see among others, Faia and Monacelli (2007), Nisticò (2016), and Hansen (2018)).
} 
Welfare Costs Inflation and Wage Inflation

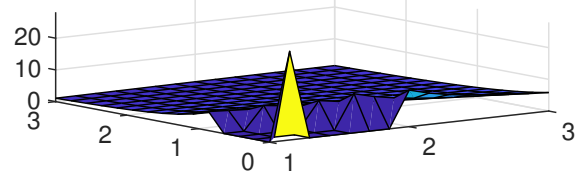

$\stackrel{\kappa}{\kappa} \underset{\pi}{\kappa}$ Welfare Costs Inflation and Loans

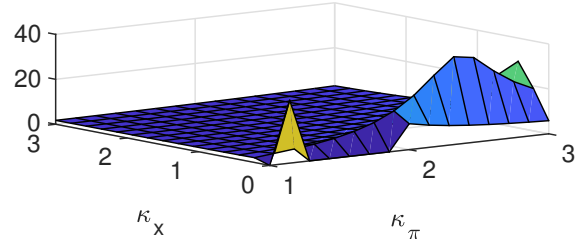

Welfare Costs Inflation and Output Gap

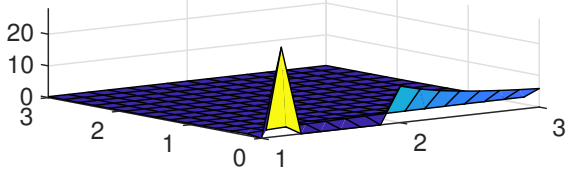

$\kappa y$

Welfare Costs Inflation and Smoothing

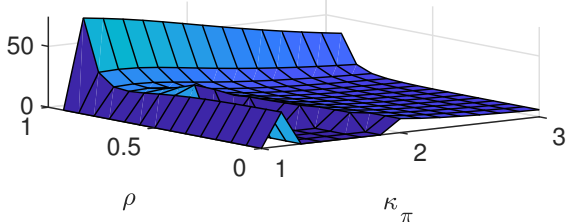

Figure 3: Welfare costs of monetary policy rules relative to the outcome under Ramsey-optimal monetary policy. The welfare costs are expressed in consumption equivalence. For each plot, two of the Taylor parameters are varied, the other policy coefficients are zero.

about similarly well, suggesting only a minimal trade-off between both policies. Neither an inflation rule that is augmented by high smoothing parameters nor a rule that accounts for the credit gap as a proxy for financial stability performs as well as the wage inflation and output gap rules.

\subsection{Welfare relevant trade-offs on basis of quadratic loss functions}

In this section, I elaborate robustness of optimal monetary policy rules on basis of quadratic loss functions. Under conventional monetary policy, there is only one instrument available, the nominal interest rate, but more than one welfare relevant aggregates. This creates trade-offs between stabilizing the volatility of welfare relevant variables.

In order to visualize the underlying trade-offs, figure 4 plots the policy frontiers for three different policy regimes under the capital quality shock. For these three policies, I allow the central bank to minimize either a quadratic loss function of a weighted average of a) inflation and wage inflation (blue circles); b) inflation and output gap (red crosses); and c) output gap and wage inflation (yellow stars). The frontiers are obtained by varying the weight $\mathcal{W}$ on variable one and the weight $1-\mathcal{W}$ on variable two in these quadratic loss functions, with $\mathcal{W} \in[0,1]$.

As shown in the first panel, the lower the volatility of inflation, the more volatile 

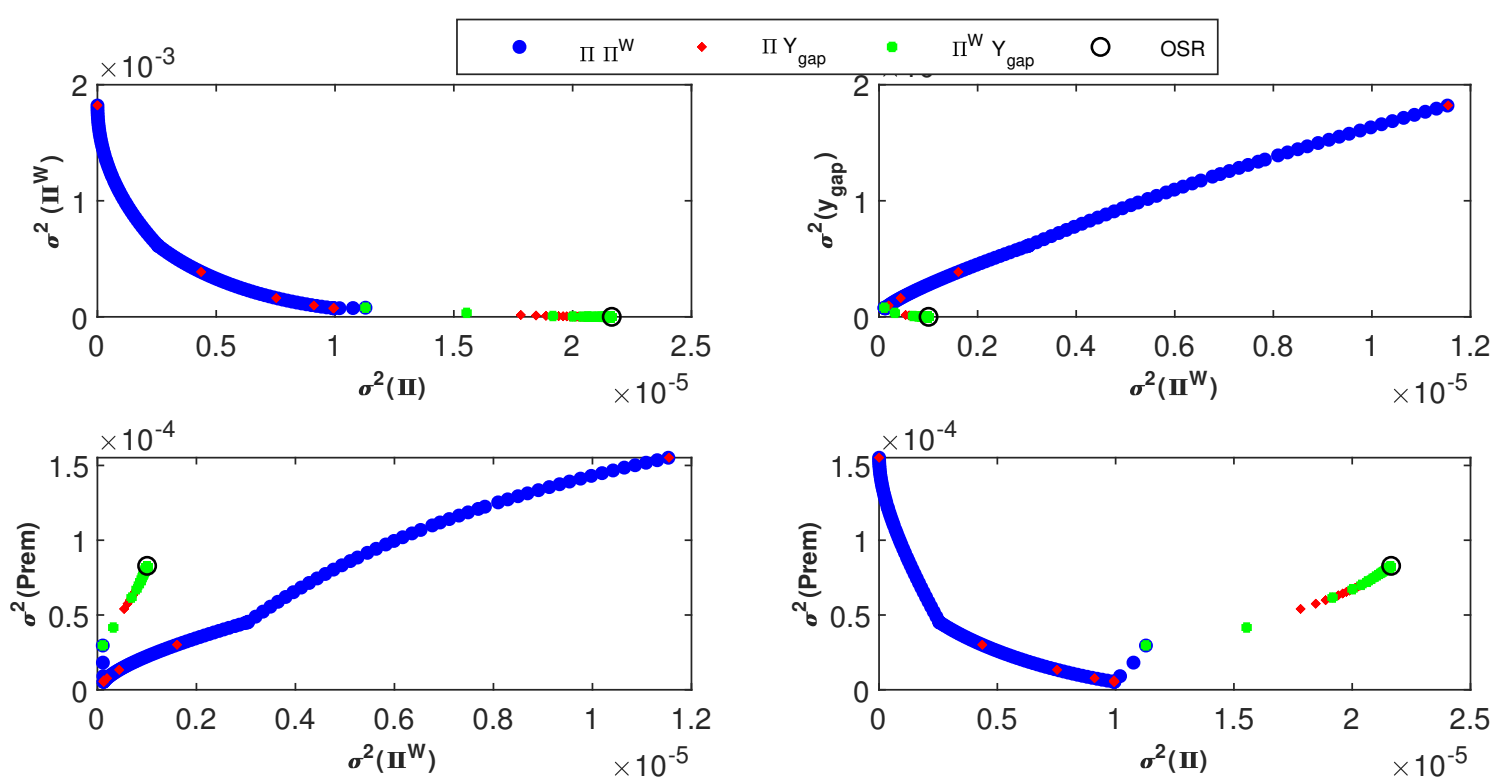

Figure 4: Policy frontiers for optimal simple rules, minimizing a quadratic loss functions. Under the policy 1 (blue circles) the central bank's objective is to stabilize a weighted average of inflation and wage inflation. The weight on both targets vary and lie in the interval $[0,1]$. Policy 2 (red crosses) stabilizes a weighted average of inflation and output gap, while policy 3 (yellow stars) stabilizes a weighted average of wage inflation and output gap. The black circle denotes the results of the optimal simple rule from table 5 .

are nominal wages. The missing trade-off between closing the output gap and wage inflation is depicted in column two, panel one. The results for the optimal simple rule indicate that the policy maker wants to close the output gap and minimize wage inflation, with the cost of a high volatility in inflation. The graphs below in the second panel, connect the volatility in wage inflation and inflation with the credit spread. Nominal wages and the credit spread can be simultaneously stabilized up to some threshold. This relationship is reversed for inflation and credit spread.

\subsection{Determinacy}

In this section, I comment on the set of policy parameters under which the model is determinant. In the literature, it is a well-established fact that, as long as the central bank reacts less than one-to-one to inflation, the model is indetermined (see Cochrane (2011) for a comprehensive discussion on this topic). However, in presence of endogenous capital, a second indeterminacy region for Taylor coefficients larger than one emerges. This second indeterminacy region is also well-established in the literature, occurring both under the assumption of a rental market for capital 


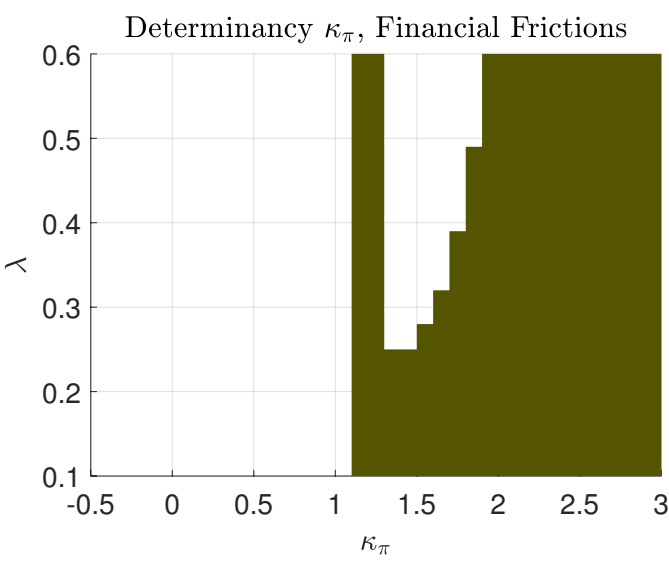

(a) Financial Frictions $\kappa_{\pi}$

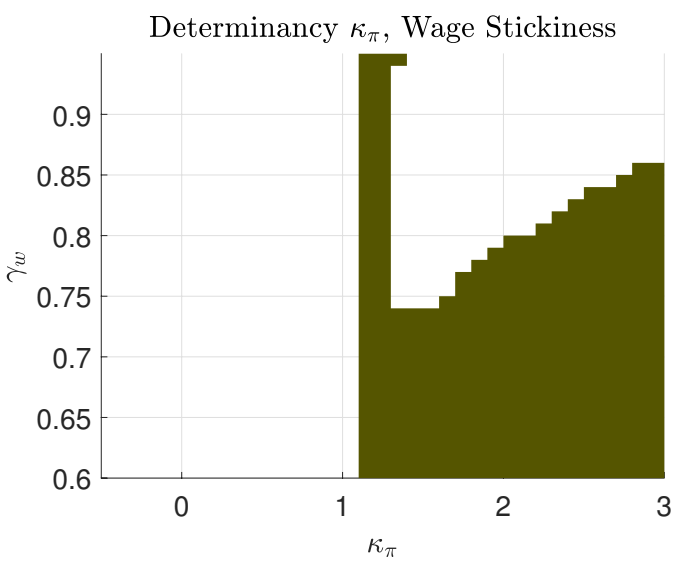

(c) With Financial Frictions

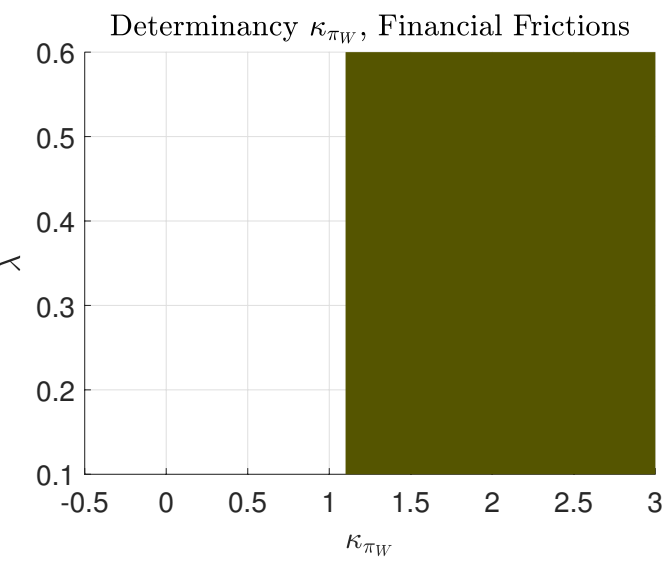

(b) Financial Frictions $\kappa_{\pi_{W}}$

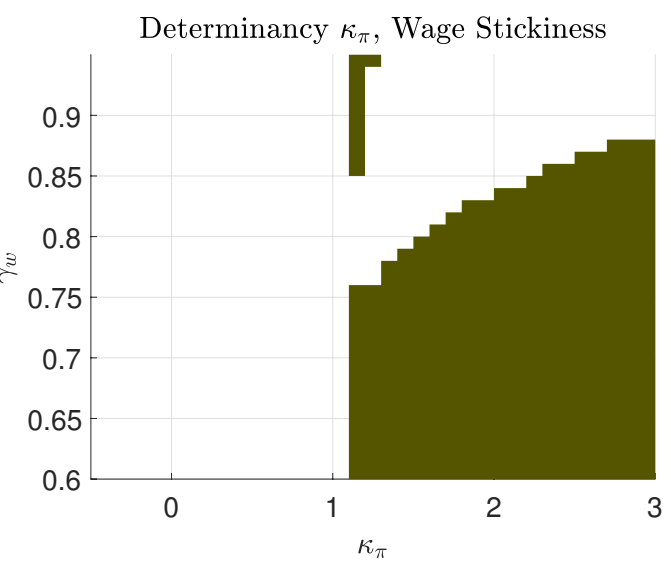

(d) No Financial Frictions

Figure 5: Determinacy region of price inflation and wage inflation coefficients for different degrees of financial frictions and different degrees of wage stickiness. The $\lambda$ parameter denotes the fraction of bankers diverting assets, $\gamma_{w}$ denotes the share of households not resetting their wages. White colored regions define the parameter sets for which the Blanchard Kahn condition is violated.

and under the assumption of firm-specific capital (Sveen and Weinke (2005) and Carlstrom and Fuerst (2005)). This second indeterminacy region stems from selffulfilling investment booms. With sticky wages present, the region of indeterminacy increases for given values of the inflation Taylor coefficient (see Sveen and Weinke $(2007))$.

Figure 5 panel (c) and panel (d) shows that the introduction of financial frictions affects the determinacy region and, thus, the effectiveness under inflationstabilizing policies. Under the benchmark calibration with the share of divertable assets $\lambda=0.381$, the region of indeterminacy is larger for a given value of wage stickiness. This is explained by the wedge between capital rental rate and the risk 
free rate. Lowering/Increasing the policy rate does not one-to-one transmit to a lowering/increase in the borrowing rate. In line with the results in previous parts of this paper, the investment sunspot shock lowers marginal product of capital but increases the marginal cost of firms. However, the latter does not rise enough to compensate for the decline in marginal product of capital. The borrowing rate drops. The central bank reacts to the rise in marginal costs by initially increasing the policy rate. However, once newly installed capital becomes productive, marginal costs fall, causing periods of deflation. Thus, the reaction by the inflation-stabilizing central bank during the deflationary period, will cause the real interest rate to fall. A sufficiently high degree of nominal frictions reduces the long-run real interest rate. Together with the dynamics of the borrowing rate, the long-run credit spread is low, such that investment booms become self-fulfilling. A much stronger reaction to inflation is needed to prevent the credit spread from falling and to prevent a self-fulfilling investment boom.

Holding the nominal frictions constant and varying the degree of financial frictions demonstrates that the region of indeterminacy is continually increasing. This result is depicted in figure 5 panel (a). By increasing the degree of financial frictions, policy makers are required to put a higher weight on price inflation stabilization to ensure a unique equilibrium, as shown panel (a) of figure 5.

The fall dominating substitution effect explains why the region of determinacy does not change for different degrees of financial frictions when the interest rate policy is responding to wage inflation, as shown in panel (b) of figure 5. By stabilizing nominal wages, the policy maker does stabilize the expected marginal product of labor and, hence, the marginal product of capital. The higher relative credit spread mitigates the boom in investment.

\section{Conclusion}

This paper demonstrates that the relative factor costs of goods-producing firms play an important role for credit intermediation and the profitability of the banking sec- 
tor. In particular, the level of wages, as the main determinant of firms' marginal costs, is crucial not only for the production side of the economy but also for the financial sector. The composition of input factors depends strongly on the relative factor costs. Bank lending is directly affected by these relative factor costs. This paper shows that, in presence of a financial accelerator along the lines of Gertler and Karadi (2011), the substitution effect between capital and labor plays an important role that can dominate over the scale effect. Changes in capital demand are amplified by financial frictions, augmenting the importance of wage setting for both macroeconomic activity and the welfare effects of monetary policy.

For monetary policy this implies that stabilizing inflation in a setting with financial frictions can have severe welfare costs. This effect is primarily driven by the existence of a trade-off between stabilizing inflation and stabilizing the spread between rental rate and risk free rate. The trade-off emerges from the adverse cost-push channel of monetary policy on loan intermediation that widens the credit spread. A widening of the credit spread has a large amplification effect on output fluctuations and the opening of the output gap. Stabilizing nominal wages comes close to the Ramsey optimal monetary policy in case the economy is hit by macroeconomic and financial supply-side shocks. This result even holds under completely flexible nominal wages. The surprising effectiveness of such a policy relies on the substitution effect channel. Stabilizing labor productivity reduces the expected future costs of capital while increasing the price of capital and banks' profitability. Further, after a contractionary shock, keeping nominal wages relatively constant causes an increase in firms' nominal marginal costs and inflation rises. Therefore, the real risk free rate drops, which again helps to decrease the spread in credit and mitigates the financial accelerator effect on output. 


\section{References}

Calvo, Guillermo (1983). "Staggered Prices in a Utility-Maximization Framework." In: Journal of Monetary Economics 12.3, 383-398.

Calvo, Guillermo, Fabrizio Coricelli, and Pablo Ottonello (2014). "Labor Market, Financial Crises and Inflation: Jobless and Wageless Recoveries". In: NBER Working Paper 18480, pp. 1-33.

Carlstrom, Charles T and Timothy S Fuerst (2001). "Monetary shocks, agency costs, and business cycles". In: Carnegie-Rochester Conference Series on Public Policy 54.1, pp. 1-27.

- (2005). "Investment and interest rate policy: a discrete time analysis". In: Journal of Economic Theory 123, 4-20.

Carlstrom, Charles T., Timothy S. Fuerst, and Matthias Paustian (2010). "Optimal monetary policy in a model with agency costs". In: Journal of Money, Credit and Banking 42.SUPPL. 1, pp. 37-70.

Christiano, Lawrence J, Martin Eichenbaum, and Charles L Evans (2005). "Nominal Rigidities and the Dynamic Effects of a Shock to Monetary Policy". In: Journal of Political Economy 113.1, pp. 1-45.

Christiano, Lawrence J., Martin S Eichenbaum, and Mathias Trabandt (2015). "Understanding the Great Recession". In: American Economic Journal: Macroeconomics $7.1,110-167$.

Cochrane, John H. (2011). "Determinacy and Identification with Taylor Rules". In: Journal of Political Economy 119.3, pp. 565-615.

Cúrdia, Vasco and Michael Woodford (2016). "Credit Frictions and Optimal Monetary Policy". In: Journal of Monetary Economics 84, pp. 30-65.

De Groot, Oliver and Alexander Haas (2019). "The Signalling Channel of Negative Interest Rates". In: SSRN Electronic Journal 95479.

De Paoli, Bianca and Matthias Paustian (2017). "Coordinating Monetary and Macroprudential Policies". In: Journal of Money, Credit and Banking 49.2-3, pp. 319349 . 
Demirel, Ufuk D. (2009). "Optimal monetary policy in a financially fragile economy". In: B.E. Journal of Macroeconomics 9.1, pp. 1690-1935.

ElFayoumi, Khalid (2018). "Jobless and Wageless Growth: The Composition Effects of Credit Easing". In: SSRN Electronic Journal.

Erceg, Christopher J, Dale W Henderson, and Andrew T Levin (2000). "Optimal Monetary Policy with Staggered Wage and Price Contracts". In: Journal of Monetary Economics 46.2, pp. 281-313.

Faia, Ester and Tommaso Monacelli (2007). "Optimal interest rate rules, asset prices, and credit frictions". In: Journal of Economic Dynamics and Control 31.10, pp. 3228-3254.

Fiore, Fiorella De and Oreste Tristani (2013). "Optimal Monetary Policy in a Model of the Credit Channel". In: The Economic Journal 123.571, pp. 906-931.

Galí, Jordi (2008). Monetary Policy, Inflation and the Business Cycle. Vol. 1. Princeton University Press.

Gambacorta, Leonardo and Federico M. Signoretti (2014). "Should monetary policy lean against the wind?. An analysis based on a DSGE model with banking." In: Journal of Economic Dynamics and Control 43, pp. 146-174.

Gerali, Andrea, Stefano Neri, Luca Sessa, and Federico M. Signoretti (2010). "Credit and banking in a DSGE model of the Euro area". In: Journal of Money, Credit and Banking 42.6, pp. 107-141.

Gertler, Mark and Peter Karadi (2011). "A model of unconventional monetary policy". In: Journal of Monetary Economics 58.1, pp. 17-34.

- (2013). "Qe 1 vs. 2 vs. 3...: A framework for analyzing large-scale asset purchases as a monetary policy tool". In: International Journal of Central Banking 9.SUPPL.1, pp. $5-53$.

Gertler, Mark and Nobuhiro Kiyotaki (2010). "Financial intermediation and credit policy in business cycle analysis". In: Handbook of Monetary Economics 3.C, pp. $547-599$. 
Hall, Robert E. (2011). "The long slump". In: American Economic Review 101.2, pp. 431-469.

Hansen, James (2018). "Optimal monetary policy with capital and a financial accelerator". In: Journal of Economic Dynamics and Control 92, pp. 84-102.

Hicks, J. R. (1961). "Marshall's third rule: A further comment". In: Oxford Economic Papers 13.3, pp. 262-265.

Hicks, John R. (1932). The Theory of Wages. 2nd ed. Palgrave MacMil, pp. 1-388.

Jaimovich, Nir and Henry E Siu (2012). "The Trend is the Cycle: Job Polarization and Jobless Recoveries". In: NBER Working Papers.

Mendicino, Caterina, Kalin Nikolov, Javier Suarez, and Dominik Supera (2018). "Optimal Dynamic Capital Requirements". In: Journal of Money, Credit and Banking 50.6, pp. 1271-1297.

Mian, Atif and Amir Sufi (2014). "What Explains the 2007-2009 Drop in Employment?" In: Econometrica 82.6, pp. 2197-2223.

Michelacci, Claudio and Vincenzo Quadrini (2009). "Financial markets and wages". In: Review of Economic Studies 76.2, pp. 795-827.

Nisticò, Salvatore (2016). "Optimal Monetary Policy and Financial Stability in a Non-Ricardian Economy". In: Journal of the European Economic Association 14.5, pp. $1225-1252$.

Ravenna, Federico and Carl E. Walsh (2006). "Optimal monetary policy with the cost channel". In: Journal of Monetary Economics 53.2, pp. 199-216.

Schmitt-Grohé, Stephanie and Martín Uribe (2007). "Optimal Simple and Implementable Monetary and Fiscal Rules". In: Journal of Monetary Economics 54.6, pp. $1702-1725$.

Sveen, Tommy and Lutz Weinke (2005). "New Perspectives on Capital, Sticky Prices, and the Taylor Principle". In: Journal of Economic Theory 123.1, 21-39.

- (2007). "Firm-specific capital, nominal rigidities, and the Taylor principle". In: Journal of Economic Theory 136.1, 729 - 737. 


\section{A. Two periods partial equilibrium model}

\section{A.1. Derivation of the capital factor demand elasticity}

The capital factor demand elasticity to a change in wages can be derived by starting with both equations for the factor costs, and the demand constraint for a representative firm $i$ :

$$
\begin{aligned}
\frac{W_{2}}{P_{2}} & =(1-\alpha) \frac{Y_{2}(i)}{L_{2}(i)}, \\
R_{2}^{k, n o m} & =\frac{\xi_{2} P_{2} \frac{\epsilon-1}{\epsilon} \alpha \frac{Y_{2}(i)}{\xi_{2} K_{2}(i)}}{Q_{1}^{\text {nom }}}+\frac{\xi_{2} Q_{2}^{\text {nom }}(1-\delta)}{Q_{1}^{\text {nom }}}, \\
Y_{2}(i) & =\left(\frac{P_{2}(i)}{\tilde{P}_{2}}\right)^{-\epsilon} \tilde{Y}_{2}=\left(\xi_{2} K_{2}(i)\right)^{\alpha}\left(L_{2}(i)\right)^{1-\alpha} .
\end{aligned}
$$

The equations for the banking sector can be summarized in one single equation:

$$
R_{2}^{k, n o m}=\lambda \frac{1}{\beta}-\frac{N_{1}}{\beta Q_{1}^{n o m} K_{2}} .
$$

In the following I will drop the index $i$ for the representative firm.

As a first step I introduce some terms related to the Cobb-Douglas production function, that will simplify the following derivations. The representative firm's production function and the marginal products can be written as:

$$
\begin{aligned}
Y_{2} & =F\left(K_{2}, L_{2}\right)=\left(\xi_{2} K_{2}\right)^{\alpha}\left(L_{2}\right)^{1-\alpha} \\
F_{L} & =(1-\alpha) \frac{Y_{2}}{L_{2}} \\
F_{K} & =\alpha \frac{Y_{2}}{\xi_{2} K_{2}} \\
F_{L L} & =-\frac{K}{L} F_{L K} \\
F_{K K} & =-\frac{L}{K} F_{L K}
\end{aligned}
$$


For future reference the definition for the elasticity of substitution between both factor inputs will be useful:

$$
\begin{aligned}
\sigma & =\frac{\partial \frac{K_{2}}{L_{2}}}{\partial M R S} \text { with } M R S=\frac{d K}{d L}=-\frac{F_{L}}{F_{K}} \\
\sigma & =\frac{F_{K} F_{L}}{Y_{2} F_{L K}} .
\end{aligned}
$$

These definitions are in line with Hicks (1932). The derivation for the elasticity of substitution is available upon request.

In the following I derive the effect of a change in wages on firm's labor and capital input, and the price of the consumption good. I do so by computing the total differential of equation (A.1)-(A.4).

\section{A.1.1. Goods market clearing}

The total differential with respect to a change in wages is given by:

$$
\begin{aligned}
-\epsilon \tilde{Y}_{2}\left(\frac{P_{2}}{\tilde{P}_{2}}\right)^{-\epsilon-1} \frac{1}{\tilde{P}_{2}} \frac{\partial P_{2}}{\partial W_{2}} & =F_{K} \frac{\partial K_{2}}{\partial W_{2}}+F_{L} \frac{\partial L_{2}}{\partial W_{2}} \\
-\epsilon \tilde{Y}_{2}\left(\frac{P_{2}}{\tilde{P}_{2}}\right)^{-\epsilon} \frac{1}{\tilde{P}_{2}} \frac{\partial P_{2}}{\partial W_{2}} & =F_{K} \frac{\partial K_{2}}{\partial W_{2}}+F_{L} \frac{\partial L_{2}}{\partial W_{2}} \\
-\epsilon \frac{Y_{2}}{P_{2}} \frac{\partial P_{2}}{\partial W_{2}} & =F_{K} \frac{\partial K_{2}}{\partial W_{2}}+F_{L} \frac{\partial L_{2}}{\partial W_{2}} .
\end{aligned}
$$

Eventually the total differential can be written as:

$$
0=\epsilon Y_{2} \frac{\partial P_{2}}{\partial W_{2}}+R_{2}^{k, a d j} \frac{\epsilon}{\epsilon-1} \frac{\partial K_{2}}{\partial W_{2}}+W_{2} \frac{\epsilon}{\epsilon-1} \frac{\partial L_{2}}{\partial W_{2}}
$$

with $R_{2}^{k, a d j}=\frac{R_{2}^{k} Q_{1}^{n o m}}{\xi_{2}}-Q_{2}^{\text {nom }}(1-\delta)$ 


\section{A.1.2. Labor demand equation}

The labor demand equation can be simplified to

$$
W_{2}=P_{2} F_{L} \frac{\epsilon-1}{\epsilon}
$$

and the total differential is then given by:

$$
\begin{aligned}
\frac{\partial W_{2}}{\partial W_{2}} & =\frac{\epsilon-1}{\epsilon}\left(F_{L} \frac{\partial P_{2}}{\partial W_{2}}+P_{2}\left[F_{L L} \frac{\partial L_{2}}{\partial W_{2}}+F_{L K} \frac{\partial K_{2}}{\partial W_{2}}\right]\right) \\
1 & =\frac{\epsilon-1}{\epsilon}\left(\frac{W_{2}}{P_{2}} \frac{\epsilon}{\epsilon-1} \frac{\partial P_{2}}{\partial W_{2}}+P_{2}\left[-\frac{K_{2}}{L_{2}} F_{L K} \frac{\partial L_{2}}{\partial W_{2}}+F_{L K} \frac{\partial K_{2}}{\partial W_{2}}\right]\right) \\
\frac{\epsilon}{\epsilon-1} & =\frac{W_{2}}{P_{2}} \frac{\epsilon}{\epsilon-1} \frac{\partial P_{2}}{\partial W_{2}}+P_{2} F_{L K}\left[\frac{\partial K_{2}}{\partial W_{2}}-\frac{K_{2}}{L_{2}} \frac{\partial L_{2}}{\partial W_{2}}\right] \\
\frac{F_{L} F_{K}}{F_{L K} \frac{\epsilon}{\epsilon-1}} & =\frac{W_{2} F_{L} F_{K}}{P_{2} F_{L K}} \frac{\epsilon}{\epsilon-1} \frac{\partial P_{2}}{\partial W_{2}}+P_{2} F_{L} F_{K}\left[\frac{\partial K_{2}}{\partial W_{2}}-\frac{K_{2}}{L_{2}} \frac{\partial L_{2}}{\partial W_{2}}\right] \\
\sigma Y_{2} \frac{\epsilon}{\epsilon-1} & =\frac{W_{2}}{P_{2}} \sigma Y_{2} \frac{\epsilon}{\epsilon-1} \frac{\partial P_{2}}{\partial W_{2}}+\left(\frac{R_{2}^{k} Q_{1}^{n o m}}{\xi_{2}}-Q_{2}^{n o m}(1-\delta)\right) \frac{\epsilon}{\epsilon-1} F_{L}\left[\frac{\partial K_{2}}{\partial W_{2}}-\frac{K_{2}}{L_{2}} \frac{\partial L_{2}}{\partial W_{2}}\right] \\
\frac{\sigma Y_{2}}{F_{L}} & =\frac{W_{2}}{P_{2} F_{L}} \sigma Y_{2} \frac{\partial P_{2}}{\partial W_{2}}+\left(\frac{R_{2}^{k} Q_{1}^{n o m}}{\xi_{2}}-Q_{2}^{n o m}(1-\delta)\right)\left[\frac{\partial K_{2}}{\partial W_{2}}-\frac{K_{2}}{L_{2}} \frac{\partial L_{2}}{\partial W_{2}}\right] .
\end{aligned}
$$

This expression can finally be written as:

$$
\frac{\sigma Y_{2}}{F_{L}}=\frac{\epsilon-1}{\epsilon} \sigma Y_{2} \frac{\partial P_{2}}{\partial W_{2}}+R_{2}^{k, a d j} \frac{\partial K_{2}}{\partial W_{2}}-R_{2}^{k, a d j} \frac{K_{2}}{L_{2}} \frac{\partial L_{2}}{\partial W_{2}}
$$

with $R_{2}^{k, a d j}=\frac{R_{2}^{k} Q_{1}^{\text {nom }}}{\xi_{2}}-Q_{2}^{\text {nom }}(1-\delta)$.

\section{A.1.3. Capital demand equation}

The capital demand equation (A.2) can be combined with the optimality condition for the banking sector (A.4) to the following:

$$
\lambda \frac{1}{\beta}=\frac{N_{1}}{\beta Q_{1}^{\text {nom }} K_{2}}+\frac{\xi_{2} P_{2} \frac{\epsilon-1}{\epsilon} F_{K}}{Q_{1}^{\text {nom }}}+\frac{\xi_{2} Q_{2}^{\text {nom }}(1-\delta)}{Q_{1}^{\text {nom }}} .
$$

Remember, that the price of capital and the net worth are assumed to be constant in the stylized partial equilibrium model. 
The total differential with respect to a change in wages is then given by:

$$
\begin{aligned}
& 0=-\frac{N_{1}}{\beta Q_{1}^{\text {nom }} K_{2}^{2}} \frac{\partial K_{2}}{\partial W_{2}}+\xi_{2} \frac{\epsilon-1}{\epsilon}\left[\frac{F_{K}}{Q_{1}^{\text {nom }}} \frac{\partial P_{2}}{\partial W_{2}}+\frac{P_{2}}{Q_{1}^{\text {nom }}}\left(F_{K K} \frac{\partial K_{2}}{\partial W_{2}}+F_{K L} \frac{\partial L_{2}}{\partial W_{2}}\right)\right] \\
& 0=-\frac{N_{1}}{\beta Q_{1}^{\text {nom }} K_{2}^{2}} \frac{\epsilon}{\epsilon-1} \frac{\partial K_{2}}{\partial W_{2}}+\xi_{2}\left[\frac{F_{K}}{Q_{1}^{\text {nom }}} \frac{\partial P_{2}}{\partial W_{2}}+\frac{P_{2} F_{L K}}{Q_{1}^{\text {nom }}}\left(\frac{\partial L_{2}}{\partial W_{2}}-\frac{L_{2}}{K_{2}} \frac{\partial K_{2}}{\partial W_{2}}\right)\right] \\
& 0=-\frac{N_{1} F_{L}}{\beta K_{2}^{2}} \frac{\epsilon}{\epsilon-1} \frac{\partial K_{2}}{\partial W_{2}}+\xi_{2}\left[F_{K} F_{L} \frac{\partial P_{2}}{\partial W_{2}}+P_{2} F_{L K} F_{L}\left(\frac{\partial L_{2}}{\partial W_{2}}-\frac{L_{2}}{K_{2}} \frac{\partial K_{2}}{\partial W_{2}}\right)\right] \\
& 0=\xi_{2} F_{K} F_{L} \frac{\partial P_{2}}{\partial W_{2}}+\frac{\epsilon}{\epsilon-1}\left[\xi_{2} W_{2} F_{L K} \frac{\partial L_{2}}{\partial W_{2}}-\frac{N_{1} F_{L}}{\beta K_{2}^{2}} \frac{\partial K_{2}}{\partial W_{2}}-\xi_{2} W_{2} F_{L K} \frac{L_{2}}{K_{2}} \frac{\partial K_{2}}{\partial W_{2}}\right] \\
& 0=\frac{F_{K} F_{L}}{F_{L K}} \frac{\epsilon-1}{\epsilon} \frac{\partial P_{2}}{\partial W_{2}}+W_{2} \frac{\partial L_{2}}{\partial W_{2}}-\left[\frac{N_{1} F_{L}}{\beta K_{2}^{2} F_{L K} \xi_{2}}+W_{2} \frac{L_{2}}{K_{2}}\right] \frac{\partial K_{2}}{\partial W_{2}}
\end{aligned}
$$

The total differential can eventually written as:

$$
0=\sigma Y_{2} \frac{\epsilon-1}{\epsilon} \frac{\partial P_{2}}{\partial W_{2}}+W_{2} \frac{\partial L_{2}}{\partial W_{2}}-\left[\frac{N_{1} F_{L}}{\beta K_{2}^{2} F_{L K} \xi_{2}}+W_{2} \frac{L_{2}}{K_{2}}\right] \frac{\partial K_{2}}{\partial W_{2}}
$$

\section{A.1.4. Solving for the factor elasticities to a change in wages}

The capital factor elasticity with respect to wages can be expressed by:

$$
\eta_{K, w}^{b a n k s}=\frac{\partial K_{2}}{\partial W_{2}} \frac{W_{2}}{K_{2}}
$$

As a first step, one has to solve for the partial differential $\frac{\partial K_{2}}{\partial W_{2}}$. Equations (A.6)-(A.8) describe the system of equations. This is in matrix notation:

$$
\left.\left(\begin{array}{ccc}
\epsilon Y_{2} & \frac{\epsilon}{\epsilon-1} W_{2} & \frac{\epsilon}{\epsilon-1} R_{2}^{a d j} \\
\frac{\epsilon-1}{\epsilon} \sigma Y_{2} & -R_{2}^{a d j} \frac{K_{2}}{L_{2}} & R_{2}^{a d j} \\
\frac{\epsilon-1}{\epsilon} \sigma Y_{2} & W_{2} & -\left[\frac{N_{1} F_{L}}{\beta K_{2}^{2} F_{L K} \xi_{2}}+W_{2} \frac{L_{2}}{K_{2}}\right.
\end{array}\right]\right)=\left(\begin{array}{c}
0 \\
\frac{\sigma Y_{2}}{F_{L}} \\
0
\end{array}\right)
$$

This linear system of equations can be solved by Cramer's rule.

$$
\frac{\partial K_{2}}{\partial W_{2}}=\frac{\operatorname{det}\left(A_{1}\right)}{\operatorname{det}(A)},
$$


with

$$
\begin{gathered}
\operatorname{det}\left(A_{1}\right)=\left|\begin{array}{ccc}
\epsilon Y_{2} & \frac{\epsilon}{\epsilon-1} W_{2} & 0 \\
\frac{\epsilon-1}{\epsilon} \sigma Y_{2} & -R_{2}^{a d j} \frac{K_{2}}{L_{2}} & \frac{\sigma Y_{2}}{F_{L}} \\
\frac{\epsilon-1}{\epsilon} \sigma Y_{2} & W_{2} & 0
\end{array}\right| \\
\operatorname{det}\left(A_{1}\right)=\frac{\epsilon-1}{\epsilon} P_{2} Y_{2}^{2} \sigma(\sigma-\epsilon)
\end{gathered}
$$

and

$$
\begin{aligned}
& \operatorname{det}(A)=\left|\begin{array}{ccc}
\epsilon Y_{2} & \frac{\epsilon}{\epsilon-1} W_{2} & \frac{\epsilon}{\epsilon-1} R_{2}^{a d j} \\
\frac{\epsilon-1}{\epsilon} \sigma Y_{2} & -R_{2}^{a d j} \frac{K_{2}}{L_{2}} & R_{2}^{a d j} \\
\frac{\epsilon-1}{\epsilon} \sigma Y_{2} & W_{2} & -\left[\frac{N_{1} F_{L}}{\beta K_{2}^{2} F_{L K} \xi_{2}}+W_{2} \frac{L_{2}}{K_{2}}\right]
\end{array}\right| \\
& \left.=\mid \begin{array}{ccc}
\epsilon Y_{2} & F_{L} P_{2} & F_{K} P_{2} \\
\frac{\epsilon-1}{\epsilon} \sigma Y_{2} & -\frac{\epsilon-1}{\epsilon} \frac{K_{2} F_{K} P_{2}}{L_{2}} & \frac{\epsilon-1}{\epsilon} F_{K} P_{2} \\
\frac{\epsilon-1}{\epsilon} \sigma Y_{2} & \frac{\epsilon-1}{\epsilon} F_{L} P_{2} & -\left[\frac{N_{1} \sigma Y_{2}}{\beta \xi_{2} K_{2}^{2} F_{K}}+\frac{\epsilon-1}{\epsilon} \frac{F_{L} P_{2} L_{2}}{K_{2}}\right.
\end{array}\right] \mid \\
& =\frac{(\epsilon-1)^{2} P_{2} \sigma Y_{2}\left(\beta \xi_{2} P_{2} F_{K}^{3} K_{2}^{3}+2 \beta \xi_{2} P_{2} F_{K}^{2} F_{L} K_{2}^{2} L_{2}+\beta \xi_{2} P_{2} F_{K} F_{L}^{2} K_{2} L_{2}^{2}\right)}{\beta \xi_{2} \epsilon^{2} F_{K} K_{2}^{2} L_{2}} \\
& +\frac{(\epsilon-1) \epsilon P_{2} \sigma Y_{2}^{2} N_{1}\left(F_{K} K_{2} \epsilon+\sigma F_{L} L_{2}\right)}{\beta \xi_{2} \epsilon^{2} F_{K} K_{2}^{2} L_{2}} \\
& =\frac{\beta \xi_{2}(\epsilon-1)^{2} P_{2}^{2} \sigma Y_{2} F_{K} K_{2}\left(F_{K} K_{2}+F_{L} L_{2}\right)^{2}}{\beta \xi_{2} \epsilon^{2} F_{K} K_{2}^{2} L_{2}}+\frac{(\epsilon-1) P_{2} \sigma Y_{2}^{2} N_{1} F_{K} K_{2}\left(\epsilon+\sigma \frac{F_{L} L_{2}}{F_{K} K_{2}}\right)}{\beta \xi_{2} \epsilon F_{K} K_{2}^{2} L_{2}} \\
& =\frac{\epsilon-1}{\epsilon}\left[\frac{(\epsilon-1) P_{2}^{2} \sigma Y_{2}^{3}}{\epsilon K_{2} L_{2}}+\frac{P_{2} \sigma Y_{2}^{2} N_{1}\left(\epsilon+\sigma \frac{1-\alpha}{\alpha}\right)}{\beta \xi_{2} K_{2} L_{2}}\right] \\
& \operatorname{det}(A)=\frac{\epsilon-1}{\epsilon}\left[\frac{P_{2} \sigma Y_{2}^{2}\left[\beta \xi_{2} P_{2} Y_{2}(\epsilon-1)+N_{1}\left(\epsilon+\sigma \frac{1-\alpha}{\alpha}\right)\right]}{\beta \xi_{2} K_{2} L_{2}}\right]
\end{aligned}
$$


Combining equations (A.9),(A.11) and (A.12) yields the results for the capital factor elasticity to a change in wages, equation (8) in the main text, as the following:

$$
\begin{aligned}
\eta_{K, w}^{b a n k} & =\frac{W_{2}}{K_{2}} \frac{\beta \xi_{2} K_{2} L_{2}(\sigma-\epsilon)}{\beta \xi_{2} P_{2} Y_{2}(\epsilon-1)+N_{1}\left(\epsilon+\sigma \frac{1-\alpha}{\alpha}\right)} \\
\eta_{K, w}^{b a n k} & =[\sigma-\epsilon] \frac{\epsilon-1}{\epsilon} \frac{L_{2} * M P L_{2}}{Y_{2}(\epsilon-1)+\frac{N_{1}\left(\epsilon+\sigma \frac{1-\alpha}{\alpha}\right)}{\beta \xi_{2} P_{2}}}
\end{aligned}
$$

\section{A.2. Calibration PE model}

\begin{tabular}{c|c}
\hline \hline Description & Value \\
\hline$\alpha_{P E}$ & 0.3 \\
$\beta_{P E}$ & 0.99 \\
$\delta_{P E}$ & 0.025 \\
$\lambda_{P E}$ & 0.381 \\
$N_{1}$ & 1 \\
$Q_{1}$ & 1 \\
$Q_{2}$ & 1 \\
$w_{2}$ & 1 \\
$Y_{2}$ & 1 \\
\hline \hline
\end{tabular}

Table A1: The calibration of the two-periods partial equilibrium model.

\section{B. Appendix: Data}

Gross domestic product: US real gross domestic product, deflated, seasonally adjusted data (U.S. Bureau of Economic Analysis, Real Gross Domestic Product [GDPC1], retrieved from FRED, Federal Reserve Bank of St. Louis).

Consumption: US real consumption, deflated, seasonally adjusted data (U.S. Bureau of Economic Analysis, Real Personal Consumption Expenditures [PCECC96], retrieved from FRED, Federal Reserve Bank of St. Louis).

Business investment: US nominal gross private domestic investment: Domestic business, in billions of Dollars, seasonally adjusted data (U.S. Bureau of Economic Analysis, Gross private domestic investment: Domestic business [W987RC1Q027SBEA], 
retrieved from FRED, Federal Reserve Bank of St. Louis).

Government expenditures: US total nominal government expenditures, in billions of Dollars, seasonally adjusted data (U.S. Bureau of Economic Analysis, Government total expenditures [W068RCQ027SBEA], retrieved from FRED, Federal Reserve Bank of St. Louis).

GDP deflator: US gross domestic product price deflator, index $2012=100$, seasonally adjusted data (U.S. Bureau of Economic Analysis, Gross Domestic Product: Implicit Price Deflator [GDPDEF], retrieved from FRED, Federal Reserve Bank of St. Louis).

Bank equity: US total equity capital for commercial banks, thousands of Dollars, not seasonally adjusted (Federal Financial Institutions Examination Council (US), Total Equity Capital for Commercial Banks in United States [USTEQC], retrieved from FRED, Federal Reserve Bank of St. Louis).

Return on bank equity: US banks' return on average equity, percent, not seasonally adjusted (Federal Financial Institutions Examination Council (US), Return on Average Equity for all U.S. Banks [USROE], retrieved from FRED, Federal Reserve Bank of St. Louis).

Commercial loan rate: US loan rate for commercial and industry loans, percent, not seasonally adjusted (Board of Governors of the Federal Reserve System (US), Weighted-Average Effective Loan Rate for All Commercial and Industry Loans, Moderate Risk, All Commercial Banks (DISCONTINUED) [EEAMNQ], retrieved from FRED, Federal Reserve Bank of St. Louis).

Commercial loans: US commercial and industry loans, in billions of Dollars, 
seasonally adjusted (Board of Governors of the Federal Reserve System (US), Commercial and Industrial Loans, All Commercial Banks [BUSLOANS], retrieved from FRED, Federal Reserve Bank of St. Louis).

Hourly wages: US average hourly earnings in production, Dollars per head, seasonally adjusted (U.S. Bureau of Labor Statistics, Average Hourly Earnings of Production and Nonsupervisory Employees: Total Private [AHETPI], retrieved from FRED, Federal Reserve Bank of St. Louis).

Hours worked: US weekly hours worked in manufacturing, in hours, seasonally adjusted (Organization for Economic Co-operation and Development, Weekly Hours Worked: Manufacturing for the United States [HOHWMN02USQ065S], retrieved from FRED, Federal Reserve Bank of St. Louis).

FED funds rate: US effective federal funds rate, in percent, not seasonally adjusted (Board of Governors of the Federal Reserve System (US), Effective Federal Funds Rate [FEDFUNDS], retrieved from FRED, Federal Reserve Bank of St. Louis).

Employment: US all employment, total nonfarm payrolls, in thousands of persons, seasonally adjusted (U.S. Bureau of Labor Statistics, All Employees: Total Nonfarm Payrolls [PAYEMS], retrieved from FRED, Federal Reserve Bank of St. Louis).

Firm leverage: Total assets of non-financial corporate businesses over non-financial corporate equity capital, share, seasonally adjusted (own calculations).

Bank leverage: Total assets of all commercial banks over commercial banks' total equity capital, share, seasonally adjusted (own calculations). 


\section{Appendix: General equilibrium model}

\section{C.1. Tables and figures}

\begin{tabular}{llc}
\hline \hline & Parameter & Value \\
\hline Disutility of labor & $\chi$ & 1 \\
Capital share in production & $\alpha$ & 0.33 \\
Household's discount rate & $\beta$ & 0.99 \\
Steady State depreciation rate & $\delta$ & 0.025 \\
Taylor coefficient inflation & $\kappa^{\pi}$ & 1.5 \\
Taylor coefficient output gap & $\kappa^{y}$ & 0.125 \\
Taylor coefficient wage inflation & $\kappa^{\pi_{w}}$ & 0 \\
Interest rate smoothing & $\rho$ & 0.8 \\
Calvo parameter prices & $\gamma_{p}$ & 0.75 \\
Calvo parameter wages & $\gamma_{w}$ & 0.75 \\
Price indexation & $\gamma_{i n d, p}$ & 0.25 \\
Wage indexation & $\gamma_{i n d, w}$ & 0.25 \\
\hline \hline
\end{tabular}

Table A2: Preset parameters. 


\begin{tabular}{l|cc|cc}
\hline \hline & \multicolumn{2}{|c}{ Productivity Shock } & \multicolumn{2}{c}{ Monetary Shock } \\
& $\gamma_{p}=0.75$ & $\gamma_{w}=0.75 \gamma_{p}=0.75$ & $\gamma_{p}=0.75$ & $\gamma_{w}=0.75 \gamma_{p}=0.75$ \\
\hline Policy Rules & \multicolumn{2}{|c}{ Welfare Costs } & \multicolumn{2}{c}{ Welfare Costs } \\
\hline$\kappa_{\pi}=1.75$ & 0.0118 & 0.0126 & 0.0257 & 0.0456 \\
$\kappa_{\pi_{W}}=1.75$ & 0.0143 & 0.0135 & 0.0194 & 0.0397 \\
$\kappa_{\pi}=1.75, \kappa_{y}=0.125$ & 0.0140 & 0.0208 & 0.0190 & 0.0215 \\
$\kappa_{\pi_{w}}=1.75, \kappa_{y}=0.125$ & 0.0150 & 0.0177 & 0.0138 & 0.0238 \\
$\kappa_{\pi}=1.75, \kappa_{\pi_{W}}=1.75$ & 0.0092 & 0.0121 & 0.0086 & 0.0192 \\
$\kappa_{\pi}=5$ & & & & \\
$\kappa_{\pi_{W}}=5$ & 0.0211 & 0.0307 & 0.0143 & 0.0122 \\
$\kappa_{y}=5$ & 0.0103 & 0.0093 & 0.0023 & 0.0236 \\
Optimal Simple Rule & 0.0615 & 0.0624 & 0.0005 & 0.0006 \\
\hline \hline
\end{tabular}

Table A3: Welfare costs of an one standard deviation negative productivity shock and a contractionary monetary policy shock for a selection of policy rules. The costs of welfare are expressed in consumption equivalents relative to the Ramsey-optimal monetary policy. In the specification presented in the first column nominal wages are perfectly flexible. The second column's results are based on the specification with both sticky wages and sticky prices.

\begin{tabular}{l|cc|cc}
\hline \hline & \multicolumn{3}{|c}{ Preference Shock } & \multicolumn{2}{c}{ Investment Elast. Shock } \\
& $\gamma_{p}=0.75$ & $\gamma_{w}=0.75 \gamma_{p}=0.75$ & $\gamma_{p}=0.75$ & $\gamma_{w}=0.75 \gamma_{p}=0.75$ \\
\hline Policy Rules & \multicolumn{2}{|c}{ Welfare Costs } & \multicolumn{2}{c}{ Welfare Costs } \\
\hline$\kappa_{\pi}=1.75$ & 0.0201 & 0.0899 & 0.0303 & 0.6332 \\
$\kappa_{\pi_{W}}=1.75$ & 0.0194 & 0.0397 & 0.0233 & 0.1758 \\
$\kappa_{\pi}=1.75, \kappa_{y}=0.125$ & 0.0213 & 0.1360 & 0.0336 & 0.1380 \\
$\kappa_{\pi_{W}}=1.75, \kappa_{y}=0.125$ & 0.0247 & 0.2826 & 0.0242 & 0.0387 \\
$\kappa_{\pi}=1.75, \kappa_{\pi_{w}}=1.75$ & 0.0187 & 0.0540 & 0.0226 & 0.1317 \\
$\kappa_{\pi}=5$ & & & & 0.1014 \\
$\kappa_{\pi_{W}}=5$ & 0.0180 & 0.1008 & 0.0245 & 0.0563 \\
$\kappa_{y}=5$ & 0.0183 & 0.0434 & 0.0220 & 0.0211 \\
Optimal Simple Rule & 0.0205 & 0.2880 & 0.0239 & 0.0213 \\
\hline \hline
\end{tabular}

Table A4: Welfare costs of a shcok to consumption preferences and to investment elasticity for a selection of policy rules. The costs of welfare are expressed in consumption equivalents relative to the Ramsey-optimal monetary policy. In the specification presented in the first column nominal wages are perfectly flexible.. The second column's results are based on the specification with both sticky wages and sticky prices. 